Portland State University

PDXScholar

\title{
Investigating the Relationship Between Supervisor Status and the Modus Operandi of Juvenile Sexual Offenders: a Routine Activity Theory Perspective
}

Kelly E. Stewart

Portland State University

Follow this and additional works at: https://pdxscholar.library.pdx.edu/open_access_etds

Part of the Psychology Commons

Let us know how access to this document benefits you.

\section{Recommended Citation}

Stewart, Kelly E., "Investigating the Relationship Between Supervisor Status and the Modus Operandi of Juvenile Sexual Offenders: a Routine Activity Theory Perspective" (2017). Dissertations and Theses. Paper 3469.

https://doi.org/10.15760/etd.5353

This Thesis is brought to you for free and open access. It has been accepted for inclusion in Dissertations and Theses by an authorized administrator of PDXScholar. Please contact us if we can make this document more accessible: pdxscholar@pdx.edu. 
Investigating the Relationship Between Supervisor Status and the Modus Operandi of Juvenile Sexual Offenders:

A Routine Activity Theory Perspective

by

Kelly E. Stewart

A thesis submitted in partial fulfillment of the requirements for the degree of

Master of Science

in

Psychology

Thesis Committee:

Keith Kaufman, Chair

Andrew Mashburn

Greg Townley

Portland State University

2017 
Abstract

A significant proportion of child sexual abuse perpetration is committed by juvenile sexual offenders (JSOs), a subgroup of offenders whose patterns of offending, or "modus operandi," have been found to be markedly different compared to their adult counterparts (Kaufman et al., 1996; Kaufman et al., 1998). Many of these JSOs commit sexual abuse perpetration while acting as a babysitter, or a temporary supervisor to their victim. The present study investigates the routine activities of JSOs and their victims' caregivers that are associated with the JSO being placed into a supervisory role. The study also investigates subgroup differences in the use of modus operandi strategies between JSO supervisors and non-supervisors. Data from this study included 370 JSO participants from four states. Results indicated that parents needs for childcare assistance predicts JSO supervisor status over perpetrators efforts to get the child alone and disruptions to parents lives. Furthermore, JSO acting as a supervisor was associated with more frequent use of modus operandi strategies overall and more frequent use of bribes and enticements to gain their victims compliance. There were no differences between JSO supervisors and non-supervisors on the threats and coercion subscale. Finally, no victim characteristics, JSO characteristics, or disruptions to parents lives, significantly moderated the relationship between JSO supervisor status and strategic grooming. Findings have important implications for research and policy related to child sexual abuse prevention and intervention. 


\section{Acknowledgements}

I would like to thank my advisor Dr. Keith Kaufman, as well as my committee members Dr. Greg Townley and Dr. Andy Mashburn, for their guidance and input throughout this process. I would also like to thank my family, particularly my mom, for their support and encouragement. 
Table of Contents

Abstract

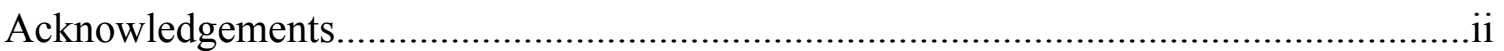

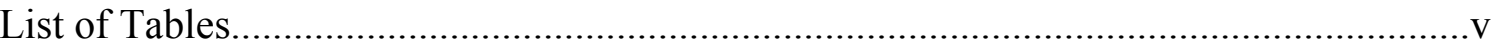

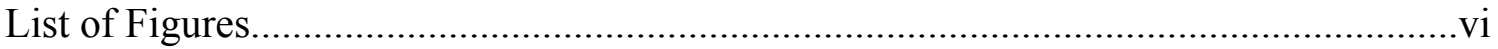

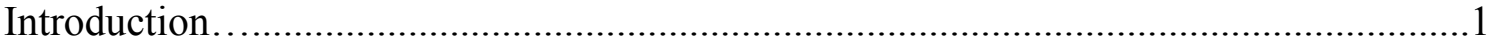

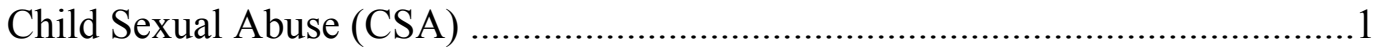

Defining the Problem.............................................................................2

Scope of the Problem................................................................... 2

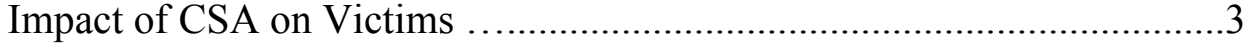

Theory-Driven Approaches to CSA Prevention.....................................................4

Rational Choice Theory (RCT) ..........................................................4

Routine Activity Theory (RAT) .........................................................6

The Public Health Model.........................................................................8

The Focus of Prevention Initiatives.......................................... 9

Timing of Prevention Interventions ...........................................9

Who Prevention Targets............................................................. 11

The Situational Prevention Approach (SPA) ..................................................... 11

Strengths and Weaknesses of the Situational Prevention

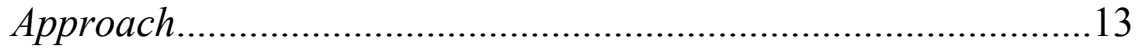

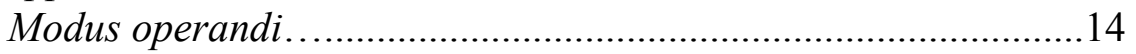

The Application of Modus Operandi to Prevention Strategies..... 16

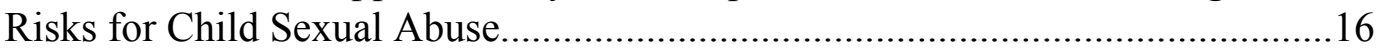

Adult Versus Juvenile Sexual Offenders.............................................. 17

Male Versus Female Offenders............................................................18

Intra- Versus Extra-Familial Offenders................................................. 18

What Puts Children at Risk for CSA? .....................................................19

Child Supervision and CSA Perpetration......................................................21

Parental Monitoring and CSA Perpetration.........................................22

Defining Parental Monitoring..................................................22

Measuring Parental Monitoring..............................................22

Parental Monitoring Findings................................................24

"Guardianship" and Routine Activity Theory.....................................25

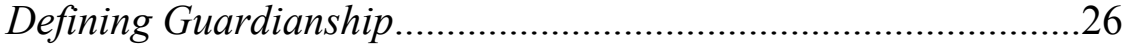

Guardianship Findings.......................................................26

Extending Guardianship.......................................................27

A Critique of the Current Literature.................................................................28

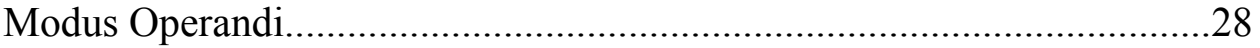

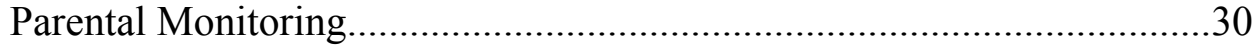

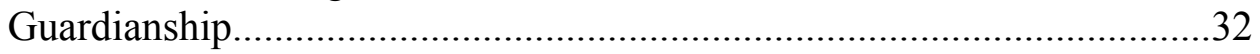

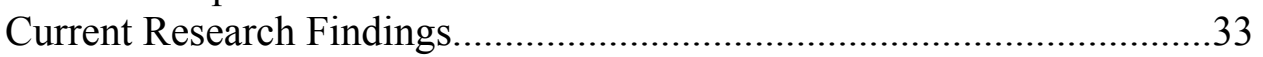

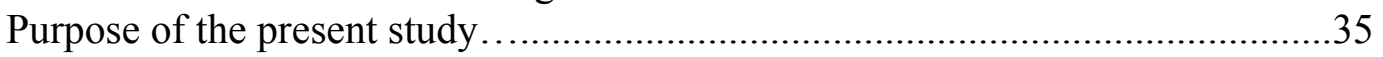

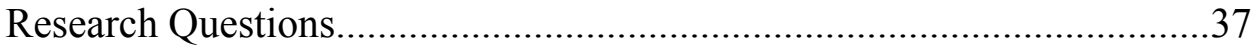

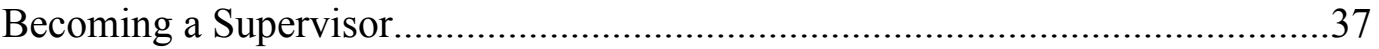

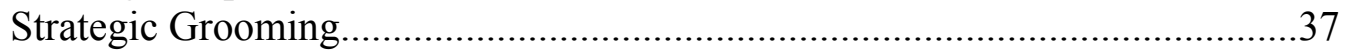




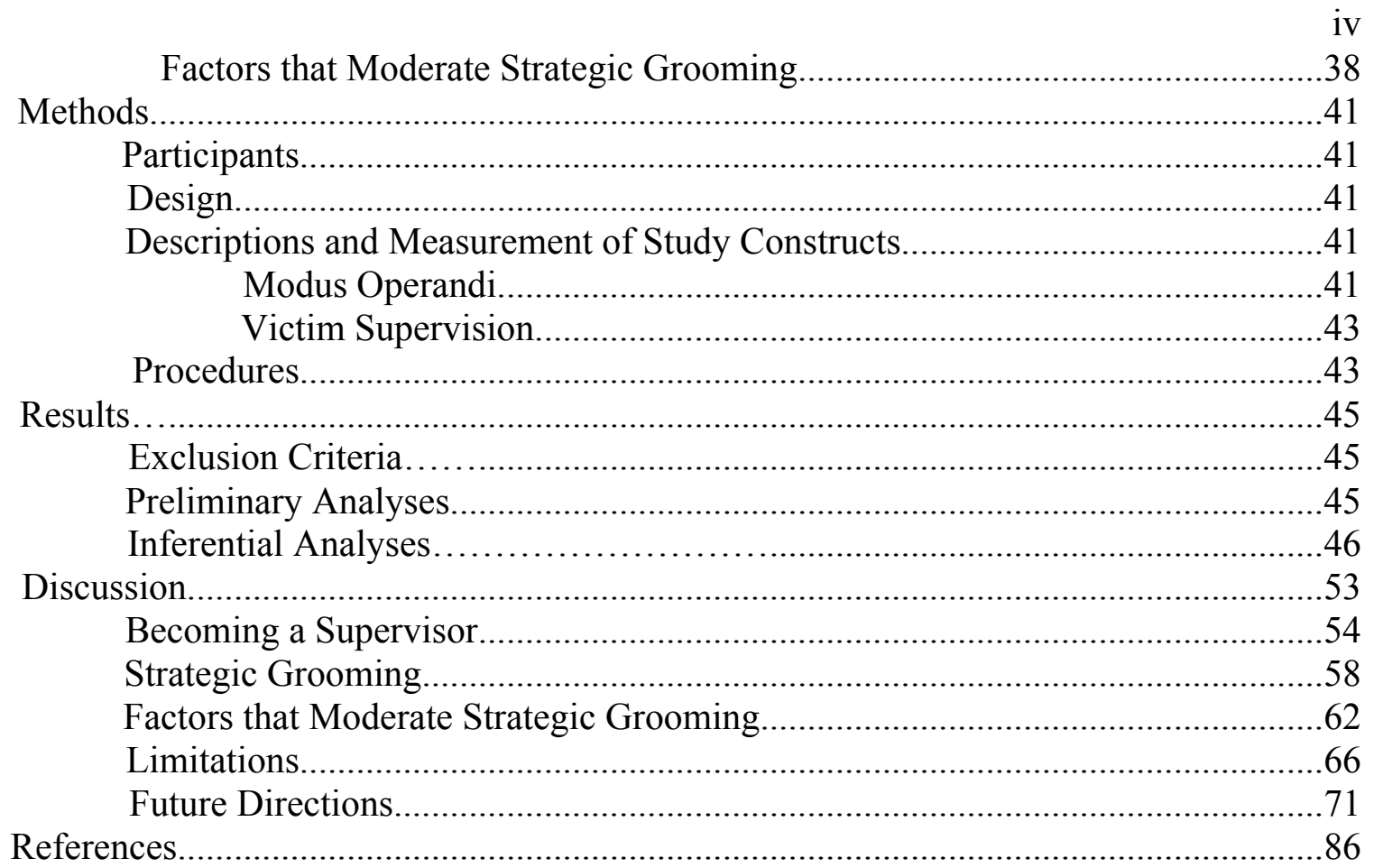


List of Tables

Table 1.

Subscale Reliability and Individual Items for the Adolescent Modus Operandi Questionnaire

Table 2.

Subscale Reliability and Individual Items for the Supervision Questionnaire

Table 3.

Modus Operandi Mean Scores 
List of Figures

Figure 1.

The Situational Prevention Model of

Child and Adolescent Sexual Abuse

Figure 2.

Research Question One: Becoming a Supervisor

Figure 3.

Research Question Two: Strategic Grooming

Figure 4.

Research Question 3: Factors that Moderate Strategic Grooming

Figure 5.

Adolescent Modus Operandi Questionnaire Continuum of Abuse

Figure 6.

Group Distribution of Strategic Grooming Scores

Figure 7.

Group Distribution of Bribes to Gain Victim

Compliance Scores

Figure 8.

Average Frequency of Modus Operandi Strategies Used According to JSO Supervisor Status and Number of Previous Victims 


\section{Introduction}

Child Sexual Abuse (CSA) perpetration is a serious and pervasive problem with detrimental impacts. Several theories exist that provide a framework for understanding CSA perpetration and CSA prevention including Rational Choice Theory, Routine Activity Theory, the Public Health Model, and the Situational Prevention Approach. Risks associated with CSA perpetration include age, gender and familial status of the offender, as well as certain characteristics of victims that put them at heightened vulnerability. One important protective measure seems to be child supervision, which is conceptualized in both the developmental psychology literature as "parental monitoring," and the criminology literature as "guardianship." Reviewing the literatures in relation to these areas reveals important gaps in knowledge of CSA perpetration and future directions for research. The following section will provide details regarding these literatures as well as other key concepts to provide a foundation for this investigation.

\section{Child Sexual Abuse (CSA)}

In order to understand the need for CSA prevention strategies, it is first necessary to comprehend the scope and severity of the problem. While CSA is not always defined in the same way, it is widely agreed that it is a serious societal problem. Despite the development of promising interventions, numerous studies point to CSA being a highly prevalent and underreported phenomenon in communities and settings throughout the world (Fanniff \& Kolko, 2012; Finkelhor, 1994; Kaufman, Hayes \& Knox, 2010; Stoltenborgh, van Ijzendoorn, Euser, Bakermans-Kranenburg, 2011). This is an important issue to address considering the adverse short and long term consequences 
experienced by victims of CSA perpetration. The following sections will address how CSA is typically defined, estimations of the scope of the problem, as well as the impact it has on its victims.

Defining the problem. Researchers, practitioners and legislatures have failed to come to a consensus on the definition of CSA. The Centers for Disease Control (2007) defines CSA broadly as any sexual activity with an underage minor who cannot legally consent. Sexual activity can include a variety of behaviors including but not limited to inappropriate exposure, touching, genital contact, and vaginal and anal penetration. The American Academy of Pediatrics (1999) expands on this definition to include activities that violate the developmental preparedness of the child, activities that are beyond their comprehension, and activities that violate social taboos. According to the World Health Organization (Butchart, Harvey, Mian, \& Furniss, 2006) CSA perpetrators can be children or adults who have a position of power or trust over the victim. The lack of consensus over the exact definition of CSA makes it difficult to measure CSA prevalence, however experts agree that it is a pervasive problem that must be addressed.

Scope of the problem. Professional estimates, meta-analyses, and scandals in various institutions help form a picture of the pervasiveness of CSA perpetration. According to an estimate by Baker, Connaughton \& Zhang (2010), 1 in 3 girls and 1 in 7 boys in the United States are sexually molested before the age of 18, and only 10 to 35 percent of incidents involving sexual exploitation are ever reported (Baker, Connaughton \& Zhang, 2010). Additionally, a meta-analysis consisting of sixty-five articles covering sexual abuse in 22 countries indicated that $7.9 \%$ of men and $19.7 \%$ of women experienced some form of sexual abuse prior to the age of eighteen (Pereda, Guilera, 
Forns \& Gómez-Benito, 2009). This is particularly alarming considering CSA statistics are known to be under-reported. Another factor that has highlighted the problem is the recent influx of CSA related scandals in churches, schools, sports, non-profits and youthserving organizations (YSOs) that have drawn national attention to this concern (Boyle, 2014; Lanning \& Dietz, 2014; Trocmé \& Schumaker, 1999). Research in response to these scandals has provided insights into the scope of CSA. For example, a report from John Jay College (2004) identified allegations of sexual abuse in 4,392 Catholic Priests between 1950 and 2002, accounting for 3\%-6\% of all priests in the U.S. (Lanning \& Dietz, 2014). Further, estimates suggest that $6 \%$ to $10 \%$ of school children experience abuse by teachers or other staff in school settings (Colton, Roberts \& Vanstone, 2010), and $8 \%$ of Canadian athletes have experienced sexual abuse while training or competing (Parent \& Bannon, 2012). In the UK there have been reports of numerous cases of physical and sexual abuse of children in residential care (Colton, Roberts \& Vanstone, 2010), leading to estimates that $31-158$ out of every 1000 children have experienced abuse in such settings (Sullivan \& Beech, 2002; Gallagher, 1999). While a systematic mechanism for reporting and tracking organizational and institutional abuse is lacking, these findings clearly underscore a significant problem that necessitates additional attention. Taken together, these statistics indicate an ongoing concern about the very serious problem that CSA poses and the alarming number of children impacted.

Impact of CSA on victims. The widespread nature of CSA perpetration is particularly alarming due to the negative outcomes experienced by many of its victims. Short-term impacts of CSA include anxiety, depression, fear, anger, aggressive behavior and sexually inappropriate behavior (Beitchman, Zucker, Hood, \& Akman, 1991; Browne 
\& Finkelhor, 1986; Tremblay, Hébert, \& Piché, 1999). Long-term effects include anxiety, depression, self-destructive behavior, isolation, stigma, low self-esteem, distrust of others, substance abuse, sexual problems, and suicide attempts (Browne \& Finkelhor, 1986; Pérez-Fuentes, Olfson, Villegas, Morcillo, Wang \& Blanco, 2013; Tremblay, Hébert, \& Piché, 1999). However, not all victims experience the same type or severity of CSA outcomes. A number of abuse characteristics have been associated with the extent of harm experienced by CSA victims. These characteristics include a close relationship to the perpetrator, frequency and duration of the abuse, and abuse involving penetration, force, or violence (Beicher et al., 1991; Putnam, 2003). The severity of these potential negative consequences, combined with reports of the prevalence of CSA, underscore the importance of developing effective prevention and intervention strategies. To better understand CSA it is important to examine relevant theories related to its onset and maintenance.

\section{Theory-Driven Approaches to CSA Prevention}

There are several important theories with implications for describing and preventing CSA perpetration. The following sections will provide an overview of four

theories relevant to CSA prevention: Rational Choice Theory; Routine Activity Theory; the Public Health Model; and the Situational Prevention Approach. Together, these theories create a strong basis for effective evidence based prevention of CSA perpetration.

Rational Choice Theory (RCT). Rational Control Theory (RCT) is a popular theory developed by Cornish and Clarke (2002) that attempts to explain why a wide variety of crimes occur. According to RCT, an offender decides whether to commit a 
crime by weighing the cost of detection or negative outcome against whatever benefit they might derive from committing the crime, such as money, power or sexual gratification. According to RCT, the final decision to act is based upon an internal "costbenefit" analysis of these risks and rewards. RCT states that even when a crime seems impulsive or random, a series of small decisions actually precedes the final act of perpetration. Factors identified in RCT that play into whether a crime will actually take place include characteristics and past experiences of the offender, needs of the offender and their evaluation of solutions fit to meet those needs, their reaction to chance events, readiness to commit a crime, and the final decision making process of the offender (Cornish \& Clarke, 1986). Cornish and Clarke (1986) point out that criminals adopt a "crime-specific focus", meaning crimes will vary according to their specific circumstances in terms of the offenders' needs and characteristics of the setting in which the crime may occur. As time passes and an offender commits a greater number of crimes, their process of decision making will be affected by their increased level of skill and "professionalism," changes in their values and lifestyle due to their past success in committing crime, and finally, changes in their peer group that will lead to greater contact with deviant as opposed to non-deviant peers, as well as adopting the label of a criminal (Cornish \& Clarke, 1986). This theory is useful in explaining a broad variety of crimes reflecting a wide range of severity and victim impact.

RCT has been used to explain a variety of sexual and non-sexual crimes in the literature since it was first developed in the mid-1980s. For example, RCT has been successfully applied to homicide (De Souza \& Miller, 2012), assault (Reynald \& Elffers, 2009; Schreck \& Fisher 2004), burglary (Groff, 2007), cybercrime (Yar, 2005), domestic 
violence (Mannon, 1997), sexual offenses involving adults (Beauregard, Proulx, Rossmo, Leclerc, \& Allaire, 2007), and the perpetration of child sexual abuse (Leclerc, Wortley \& Smallbone, 2010). Notably, RCT has been used to explain how sexual offenders seek out child victims as well as how convicted serial sexual offenders engage in the "hunting" process (Proulx, Ouimet, \& Lachaine, 1995; Beauregard, Rossmo \& Proulx, 2007). These studies are important because they establish that sexual offenders engage in rational decision-making similar to non-sexual offenders (Beauregard, Rossmo \& Proulx, 2007). Together, these findings support the validity of RCT and highlight the importance of situational factors in determining the decisions an offender makes about whether to engage in a crime. For example, when a burglar is deciding which house to rob, they are likely to choose a house where no one is home, that is accessible to them, and away from neighbors and the street (Cornish \& Clarke, 1986). This rational approach to crime has important implications for prevention policy.

Routine Activity Theory (RAT). Developed by Larry Cohen and Marcus Felson (1979), Routine Activity Theory (RAT) focuses on environmental determinants of crime and the three underlying factors that promote the perpetration of crime. These factors include: (1) the presence of a suitable victim; (2) the presence of a motivated offender; and (3) a lack of supervision (Cohen \& Felson, 1979). RAT states that acts of crimes are not random, but rather are determined by the presence or absence of these key factors (Cohen \& Felson, 1979). First, the presence of a suitable victim is represented by both the availability and the attractiveness of a crime victim or target (e.g. specific household) to a particular offender (Cohen \& Felson, 1979). Second, the presence of a motivated offender reflects someone willing to commit a crime if the right circumstance should 
arise. Finally, a lack of supervision or guardianship is represented by the absence of any person or technology that might deter the crime from occurring (Tseloni, Wittebrood, Farrell, \& Pease, 2004). Together, these three factors contribute to an understanding of how day-to-day routines may facilitate or deter crime.

There are both strengths and limitations to RAT. For one, it has been successfully applied to a variety of crimes (Clodfelter, Turner, Hartman \& Kuhns, 2008; Franklin, Franklin, Nobles, \& Kercher, 2012; Mannon, 2007; Mustaine \& Tewksbury, 1999; Vézina, Hébert, Poulin, Lavoie., Vitaro, \& Tremblay, 2011; Tewksbury \& Mustaine, 2006). Further, RAT accounts for social structures such as families, neighborhoods and communities that may facilitate the likelihood of an offender engaging in illegal activities (Cohen \& Felson, 1979). For example, RAT helps explain how an offender might take advantage of a parent's work schedule or situations when a parent is highly distracted (e.g., caring for an ill younger child) to commit child sexual abuse. RAT also effectively explains why certain groups experience higher rates of victimization than others (Leclerc, Smallbone \& Wortley, 2013). For instance, having a mother who works outside of the home may prompt higher risk routine activities on the part of their child, such as regularly walking home alone (Finkelhor \& Baron, 1986). There are also some important limitations to RAT. For one, it was originally created to explain street crime and therefore may be more effective in explaining extra-familial abuse and less easily adapted to intra-familial CSA (Finkelhor \& Asdigian, 1996). Children who are abused by their parents or family members are more consistently subject to risks associated with routine activities. Another significant limitation of RAT is that it fails to account for personal attributes, such as gender, in explaining the perpetration of particular types of crime 
(Finkelhor \& Asdigian, 1996). In other words, female babysitters may find it easier to commit CSA without being detected due to societal beliefs that they don't pose a serious risk to children. Despite these limitations, RAT has important implications for crime prevention.

The application of RAT to a variety of problem areas, including sexual crimes, has been well documented in the literature. RAT has been found to predict the sexual harassment of college students (Clodfelter et al., 2008), dating and domestic violence (Mannon, 2007; Vézina et al., 2011), sexual assault (Franklin et al., 2012), online harassment (Bossler, Holt \& May, 2011; Marcum, Higgens \& Ricketts, 2010), the stalking of women (Mustaine \& Tewksbury, 1999) and the housing location of convicted sex offenders (Tewksbury \& Mustaine, 2006). Also, Leclerc, Wortley \& Smallbone (2010) found RAT to be predictive of the perpetration of CSA. Clearly, with its efficacy in addressing a broad array of crimes as well as its applicability specifically to sexual crimes, further research regarding RAT and CSA perpetration and further tailoring of interventions around RAT is warranted.

The Public Health Model. The public health model is an important community oriented approach to prevention. The public health approach uses a culturally competent and data informed approach to address violence at a population level (Centers for Disease Control and Prevention, 2004). There are four steps to the public health model: 1) Define the problem, 2) Identify risk and protective factors, 3) Develop and test prevention models, 4) Ensure widespread adoption (Centers for Disease Control and Prevention, 2004). In the first step, "Define the problem," data is collected to see how widespread of a problem CSA victimization is in a particular population sub-group. Sources of data for 
the scope of the problem can include community resource centers, the criminal justice system, or surveys. In the second step (i.e., Identify risk and protective factors), researchers identify the specific risk and protective factors that can be targeted for effective prevention programming. In the third stage, (i.e., Develop and test prevention strategies), data is gathered from experienced practitioners and stakeholders using methods such as interviews or focus groups to develop and determine the effectiveness of prevention strategies. At this stage, rigorous evaluations of program effectiveness and implementation are undertaken to ensure that the program is effective. The fourth and final step (i.e., Ensure widespread adoption) occurs after there is an adequate amount of data supporting the effectiveness of the program. At this stage, dissemination techniques are undertaken to ensure widespread program adoption. Techniques undertaken should include trainings, process evaluations to ensure fidelity, and outcome evaluations when applying the approach to new populations (Centers for Disease Control and Prevention, 2004). Following all four of these steps and using the most accurate evidence-based information available is critical to effectively applying the public health approach to prevention.

The Focus of Prevention Initiatives. The Center for Disease Control (2004) defines the prevention of sexual violence using the ecological model. This model accounts for the complex relationship between individual-level, interpersonal relationship-level, community-level and societal-level influences. The first level, individual-level influences refers to biological and personal history factors that relate to sexual violence risk. At the next level, interpersonal relationship-level influences refer to family, peer and intimate partner relationships that can influence behavior. Next, 
community-level influences describe characteristics of environments such as neighborhood, schools, and workplaces that can create risk. Finally, societal-level influences are macro-level factors such as laws or policies, cultural beliefs and norms that contribute to tension between groups of people. This model is often depicted as a series of four embedded concentric circles with individual-level factors occupying the inner most circle, surrounded by interpersonal-relationship factors, which are both within the community-factors circle. These three circles are contained in the outermost "socialfactors" circle. This positioning of ecological levels reflects both level specific concerns and impacts as well as the way in which the presence of positive or negative factors at any given level causes a "ripple effect" at other levels of the model. The ecological model underscores the importance of both measurement and intervention across levels to ensure effectiveness. In particular, addressing sexual violence at multiple levels can contribute to more comprehensive prevention of sexual violence (Centers for Disease Control \& Prevention, 2004). More research is needed in order to better establish risk and protective factors that exist at various levels.

Timing of Prevention Interventions. The public health model describes prevention occurring at three points in time and refers to these as: 1) Primary Prevention, 2) Secondary Prevention and 3) Tertiary Prevention (Centers for Disease Control and Prevention, 2004). At the earliest point in time, Primary Prevention targets entire populations, and aims to prevent crime before it happens by targeting risk factors. Secondary Prevention interventions target specific groups within the population who have been identified as already showing signs of being at risk to develop the target problem. Finally, Tertiary Prevention interventions take place in groups who have 
already been exposed to or experienced the target problem (Centers for Disease Control and Prevention, 2004). Ideally, prevention strategies should include interventions to address individuals at each of the three stages, while remaining largely focused on primary prevention. Unfortunately, at present, child sexual abuse (CSA) intervention strategies tend to rely more heavily on tertiary prevention approaches, while the goal is to shift the focus to primary level to prevent problems from manifesting (Smallbone, Marshall, \& Wortley, 2013).

Who Prevention Targets. Another way in which interventions can be conceptualized according to the Center for Disease Control (2004) is with an emphasis on who is the focus of the intervention. Using this conceptualization, interventions can be described as universal, selected or indicated. Universal interventions are aimed at the entire population. This can be achieved either geographically, as in targeting a school or neighborhood, or based on certain characteristics such as gender or age. Selected interventions focus on those who may be at a higher risk of sexual violence. Finally, indicated interventions are targeted at those who have already been victimized or already perpetrated sexual violence (Centers for Disease Control and Prevention, 2004). While the timing of interventions (e.g., primary, secondary, tertiary) may be more commonly referred to than whom the intervention targets, both are important in establishing a rounded conceptualization of interventions as part of the public health model.

The Situational Prevention Approach (SPA). Another promising crime prevention approach is Situational Crime Prevention (Clarke, 2005). Situational Crime Prevention is a comprehensive primary prevention model that focuses on the immediate behavioral setting in which crime takes place (Wortley \& Smallbone, 2004). It focuses 
on reducing crime through minimizing opportunities and increasing the chance of the offender being caught, as well as reducing rewards associated with perpetration and reducing the plausibility of excuses for criminal behavior (Clarke \& Homel, 2007). Kaufman and his colleagues (Kaufman, Mosher, Carter \& Estes, 2006), drawing on a combination of situational prevention, RAT and RCT, developed a version of this strategy for application in youth serving organizations that he refers to as "The Situational Prevention Approach" (SPA). At the core of the SPA model is a three-factor structure known as the "Crime Opportunity Structure," which determines whether a potential offender will decide to perpetrate against a child. Factors in this model component are Victim Characteristics, Target Locations and Facilitators (Kaufman, Mosher, Carter \& Estes, 2006). Victim Characteristics focus on attributes that make a child more or less vulnerable to abuse. Example attributes could be age, gender, developmental delays or emotional neediness, as well as attributes of others who directly affect them, such as living in a single parent household or having a parent who is a substance abuser. The second factor, Target Locations, refers to areas that are at a high risk for abuse to take place due to their isolation, limited visibility or restricted access. The third factor, Facilitators, refers to any part of the setting or organization that might make crime more likely to take place. For example, inadequate staff training or high staff turnover in an organization could act as a facilitator for the presence of risks associated with CSA perpetration. Together, these three factors provide a solid foundation for prevention efforts.

Beyond these three primary factors are several other components that contribute to the SPA model. The first is Routine Activities, which can lead to an increase in risks 
beyond the core Crime Opportunity Structure. For example, the child's routine activity of walking home alone after school my put him or her at heightened risk for abuse related to both increased Target Locations and Victim characteristics, (e.g., inadequate parental supervision). Another component is the Larger Physical Environment, which refers to attributes of buildings and neighborhoods that heighten CSA risk. Organizational Climate \& Local Community Influences also contribute to CSA perpetration risk. Policies, procedures or cultural norms in place at an organization or local government could allow for certain offenders to remain undetected, or for prevention opportunities to be missed. For example, delayed background checks could allow perpetrators access to children. Finally, offender specific factors, such as likelihood of recidivism, as well as socioeconomic structures may also increase risks of CSA with the SPA model. Together, these factors paint a comprehensive picture of risk (See Figure 1).

Strengths and Weaknesses of the Situational Prevention Approach. There are both strengths and weaknesses associated with the SPA for CSA prevention. For one, SPA strategies can be easily applied in the context of institutions, many of which have been catalysts for CSA perpetration and abuses of power over the years (e.g., the Catholic Church; Terry, Smith, Schuth, Kelly \& Vollman, 2011). The implementation of the SPA has the potential to prevent, not just CSA perpetration, but also a whole spectrum of sexual and non-sexual crimes and other dangers for children and teens (e.g., accidents, health concerns, consequences of physical aggression) in a broad variety of settings (Kaufman, Hayes \& Knox, 2010). Another strength of the SPA is that it moves away from child-focused prevention strategies that have been criticized for placing a developmentally inappropriate responsibility on children to protect themselves against 
adults and older teens, who are much better equipped to manipulate and coerce them (Renk, Liljequist, Steinberg, Bosco \& Phares, 2002). A criticism of situational prevention is that it has the potential to create rules and policies that are overly invasive. However, Wortley (2010) responds to this criticism by noting that checks and balances exist to ensure that safety is balanced with freedom, such as exists with airport security checks and bank monitoring of credit card fraud. Another criticism of situational prevention is that it only displaces crime (e.g., offenders discouraged from applying at one organization may seek a position at another), however research indicates that situational factors are important in determining the occurrence of crime, separate from criminal disposition. A study of 102 situational crime prevention evaluations found that displacement occurred in only $26 \%$ of interventions, and when displacement did occur, it tended to be of lesser severity (Guerette \& Bowers, 2009). In conclusion, the SPA is a promising new approach. Since it is relatively new approach, SPAs efficacy still must be established across various settings.

Modus Operandi. In order to effectively target sexual offenders' perpetration of CSA, the SPA can be tailored to offenders' most likely modus operandi in different types of settings (Kaufman, Hayes \& Knox, 2012). Modus operandi (MO) is defined by Kaufman et al., (1996, p. 18) as "a pattern of behaviors a perpetrator displays in the period prior to, during, \& following illicit sexual contact." Studies throughout the years have supported the existence of such patterns (Kaufman, Hilliker \& Daleiden, 1996), which involve the offenders' use of various strategies that take place along a temporal continuum. CSA modus operandi usually begins with the offender gaining access to a potential victim, "grooming" them, and in some cases their parent(s) to foster trust, 
seeking or creating opportunities to be alone with the potential victim, using bribes and enticements and/or threats and coercion to gain compliance in abusive acts, and finally, working to obtain the victim's silence about the abuse (Kaufman, Hayes \& Knox, 2012). Understanding which strategies different types of offenders (e.g., adult vs. adolescent) tend to use, based on variations in children's characteristics (e.g., young children vs. older teens, males vs. females) and key situational factors (e.g., familial, leisure setting with minimal supervision, highly structured school setting) has important implications for the development and implementation of CSA prevention and intervention strategies. For example, if a supervisor at a community center knows which strategies are typically used to gain a young child's (e.g., 6-8-year-old) trust (e.g., "special attention," gifts, time alone) by adult staff and volunteers, he or she can advocate for policies that restrict such behaviors in that setting. This may lead to more protective staff practices around such things as taking children to the rest room or contact with children outside of program hours. The supervisor can also educate staff to be more vigilant in monitoring the behavior of staff and volunteers while interacting with children in the program. These strategies can also be incorporated into the use of the SPA in the community settings to ensure that related situational risk factors (e.g., unlocked, unused rooms, staff who may be alone with children who need help in the restroom, transportation of youth on field trips) are identified and addressed to enhance youth safety (Kaufman, Hayes \& Knox, 2012). This systematic method of assessing risks and vulnerabilities and linking those risks to prevention or risk reduction strategies is fairly simple to implement and provides a basis for low cost comprehensive interventions that target crime at multiple levels (Kaufman, Hayes \& Knox, 2012). 
The Application of Modus Operandi to Prevention Strategies. As already noted, the differential use of modus operandi strategies or more frequent use of certain strategies based on offender, victim or situational characteristics is important to consider in planning CSA prevention efforts (Kaufman, Hilliker \& Daleiden, 1996) and requires careful consideration. For instance, adolescent intra-familial offenders (e.g., siblings, cousins) adopt certain types of strategies, such as giving gifts to gain victim's trust, more frequently than extra-familial adolescent offenders who may be more likely to use drugs and alcohol (Kaufman et al., 1996). Another example involves the fact that adolescent offenders appear to use more modus operandi strategies, in general, than their adult counterparts in perpetrating CSA (Kaufman et al., 1998). Finally, in a youth serving organization that has its own swimming pool, the locker room, adjacent bathroom stalls, and showers may represent especially risky settings for CSA. Recognition of these important "red flag" behaviors and high risk settings can provide a framework to assist parents, supervisors and organizational staff looking-out for particular modus operandi or "grooming patterns" to keep children in their care as safe as possible. At the same time, attention to risky settings can prompt the development of prevention strategies to address these concerns. Information regarding sexual offenders and their modus operandi can be a powerful prevention tool if delivered in an effective and culturally appropriate manner.

\section{Risks for Child Sexual Abuse}

Research reveals that CSA offenders are a heterogeneous group, yet some important distinctions have been identified. First, differences between Juvenile Sexual Offenders (JSOs) and Adult Sexual Offenders (ASOs) have been noted. A second 
distinction between intrafamilial sexual offenders and extrafamilial offenders has also been made. The following section will detail characteristics of offenders related to these important distinctions.

Adult Versus Juvenile Sexual Offenders. Early research findings on JSOs failed to account for the differences in behavior, motivation, and prognosis between JSOs and ASOs, but subsequent research has revealed that they are in fact distinct groups (Finkelhor, Ormrod \& Chaffin, 2009). JSOs represent a subtype of offender that have been found to commit over one-third of the sex crimes perpetrated against children (Finkelhor, Ormrod \& Chaffin, 2009). JSOs differ from ASOs in some key ways, including their use of different grooming strategies along the modus operandi continuum. For example, ASOs often rely on authority over their victims to gain compliance in sexually abusive behaviors and maintain victim silence following abuse onset. JSOs, on the other hand, are less likely to have as high a level of authority or control over their victims. Perhaps as a result, they are more likely to rely on a broad array of modus operandi strategies and frequent use of different strategies to gain control over their victim, such as the use of bribes and enticements, threats, coercion, and strategies to maintain silence (Kaufman et al., 1998). These major differences in grooming strategies between JSOs and ASOs have important implications for parents and caregivers who might be looking for "red flags" related to child sexual abuse.

Further, rates of CSA offending vary across the life cycle. At age 12, there is a surge in rates of sex offences that levels out at age 14. This is the peak age for JSO's offending against younger children. In later adolescence, there is an increase in sex offenses against younger teens (Finkelhor, Ormrod \& Chaffin, 2009). Later, CSA 
perpetration peaks again in men in their mid to late thirties (Abel, Osborn \& Twigg, 1993). Some would argue that sexual offending begins in adolescence and persists throughout the lifetime; however, reports from adult offenders indicate that a majority did not begin offending in their adolescence (Righthand \& Welch, 2004), and studies consistently find recidivism rates for JSOs to be low (Finkelhor, Ormrod \& Chaffin, 2009).

Male Versus Female Offenders. For the most part, both JSOs and ASOs are overwhelmingly male. A review by Cortoni and Hanson (2005) found that the prevalence of female sexual offenders ranged from .6\% in New Zealand to $8.3 \%$ in the US. Some research has focused special attention on the behavior of female offenders. For instance, research has found that female JSOs are more likely to be young, have victims who are male and related to them have multiple victims, and to have a greater frequency of offending then their male counterparts (Finkelhor, Ormrod \& Chaffin, 2009). While it is important to understand the particularities of female sexual offending, the overwhelming majority of offenders are male, suggesting that focusing on males is likely the best course for prevention.

Intra- Versus Extra-Familial Offenders. Another important distinction in CSA offender characteristics is the distinction between intra-familial and extra-familial offenders. One conceptualization of intra-familial CSA involves abuse by someone who is from the same family as the victim, and may or may not be living in the same household, such as a parent, stepparent, cousin or sibling (Fischer \& McDonald, 1998). Other studies define intra-familial CSA as abuse from any other person residing in the household, such as parents, stepparents, a parent's romantic partner, siblings or foster 
siblings (Kaufman, 1998). Extra-familial sexual abuse typically involves abuse from outside of the family. Examples of extra-familial abusers could be teachers, coaches, friends, neighbors, acquaintances or strangers (Fischer \& McDonald, 1998). Intrafamilial abuse is thought to have a longer duration and greater frequency than extrafamilial abuse (Fischer \& McDonald, 1998). Extra-familial offenders, on the other hand, are more likely to have a greater number of victims and victims who are male (Abel, Osborn \& Twigg, 1993). Intra- and extra-familial offenders have also been found to differ in their use of various modus operandi strategies. For instance, in one study, intrafamilial JSOs used a greater number of bribes and enticements to gain victim trust and compliance, and a greater number of threats and coercion to maintain silence than extrafamilial JSOs (Kaufman, Hilliker \& Daleiden, 1996). Another study comprised of both JSOs and ASOs found that extra-familial CSA offenders used alcohol and drugs to gain victim compliance more often than intra-familial CSA offenders, while intra-familial offenders are more likely to use bribes and enticements (Kaufman et al., 1998). These are important distinctions for understanding patterns of offending and their implications for prevention.

What puts children at risk for CSA? There are several factors that can potentially contribute to CSA victimization risk in children. When a number of these factors converge, it often results in a child who is at a high risk for CSA victimization. First, studies on gender differences have consistently found girls to be at a higher risk for CSA than boys. This difference likely holds true even in spite of reporting differences between genders (e.g., lower for boys; Finkelhor \& Baron, 1986). Studies examining victimization differences between males and females have found that males 
are more likely to experience intrusive forms of abuse (e.g., oral and anal abuse), and more likely to experience threats, whereas females are more likely to experience touching and fondling (Kendall-Tackett \& Simon 1992; Ketring \& Feinauer, 1999). All children are at risk in terms of age, but some research has indicated that children are most vulnerable between the ages of 7 and 13 (Finkelhor, 1994; Finkelhor \& Baron, 1986). It is important to note that this peak in offending may be skewed due to the fact that younger children are probably less likely to disclose or more likely to repress abuse. Unlike other forms of child abuse, CSA victimization does not appear to be related to social class. Another risk factor for CSA victimization is social isolation, although it is unclear whether social isolation is actually a risk factor, or whether it is a consequence of abuse. (Brown, Cohen, Johnson, \& Salzinger, 1998; Finkelhor \& Baron, 1986; Seto \& Lalumiere, 2010). Other important CSA risk factors are related to victims' parents. CSA victimization has been associated with living without their biological father or living with a stepfather, having a mother who works outside of the home, having a mother who is ill or disabled, witnessing conflict between parents and having a poor relationship with one parent (Bagley, Thurston \& Tutty, 2006; Finkelhor \& Baron, 1986; Walsh, MacMillan, \& Jamieson, 2003). Despite the existing evidence on CSA victimization risk, further research is needed to identify new risks as well as determine how risk factors may vary by developmental stage or in response to other demographic factors, such as ethnicity.

The previous sections indicate that there are many risk factors associated with CSA perpetration. These risk factors are important to consider when forming prevention interventions. Another seemingly important piece of CSA prevention is the monitoring or supervision of children. The following sections will detail how supervision has been 
conceptualized in the research literature and how it acts as a protective factor against CSA perpetration.

\section{Child Supervision and CSA Perpetration}

Within the SPA prevention framework, a lack of supervision would be related to increased risk, while better supervision is related to reduced crime perpetration (Kaufman, Hayes \& Knox, 2012). Supervision has been conceptualized differently in different literatures, but it refers to the same phenomena of tracking a child or children's whereabouts in order to protect them from harm. In the psychology literature, supervision is referred to as parental monitoring, whereas in the criminology literature, supervision is referred to as guardianship (Cohen \& Felson, 1979; Dishion \& McMahon, 1998). According to Merriam-Webster, supervision is the action or process of watching and directing what someone does or how something is done. Typically, a child's primary supervisor consists of one or more primary supervisors, such as a parent or guardian, and they may have additional supervisors throughout the day such as a teacher, camp counselor, family member or babysitter. Sometimes, a child may have multiple supervisors tracking them at once, other times, a single supervisor may have to track multiple children.

In order for CSA perpetration to occur, either parental supervision or parental judgment are often lacking (Crosson-Tower, 2005). Supervision can also affect the severity and duration of CSA. A recent study found that the mere presence of another person, when controlling for victim and situational characteristics, reduced the duration of sexual contact and reduced the occurrence of penetration in CSA by $86 \%$ (Leclerc, 
Smallbone and Wortley, 2013). This section will summarize how two conceptualizations of child supervision, parental monitoring and guardianship, are defined in the literature.

Parental Monitoring and CSA Perpetration. The parental monitoring literature provides important clues as to how parents provide effective supervisions for their kids. The following section summarizes how parental monitoring has been defined and how it has been measured, followed by a discussion of how parental monitoring has been applied to various CSA outcomes. Despite the paucity of research in this area, defining and understanding the nuances of how parental monitoring relates to CSA perpetration can be an important piece of CSA prevention.

Defining Parental Monitoring. Parental monitoring is defined as "a set of correlated parenting behaviors involving attention to and tracking of the child's whereabouts, activities, and adaptations" (Dishion \& McMahon, 1998, p. 61). In the injury prevention literature, there are three primary facets of supervision that are generally agreed upon. These include: (1) visual and auditory attention to the child; (2) physical proximity to the child; and (3) continuity of supervision (Schwebel \& Kendrick, 2009). Visual attention refers to the degree to which a caregiver watches and listens to a child. Physical proximity refers to how close the caregiver is to the child, ranging from touching, such as helping teach a small child to swim, to being in another location, such as a parent who intermittently checks on children playing in the next room. Finally, continuity of supervision is an indication of how often the caregiver is supervising versus how often they are distracted or involved in other tasks (Schwebel \& Kendrick, 2009). When implemented, these supervision components vary according to the environment and developmental needs of the child or children being monitored. For example, an older 
child playing in their room may require only intermittent auditory and visual attention, while a toddler in a busy public location would require a high continuity of attention and supervisor proximity. These facets are hierarchical, such that each is dependent on one another in order to be effective (Schwebel \& Kendrick, 2009). For example, visual attention will be ineffective if the proximity to the child is not close enough to prevent injury if a risk arises, and a supervisor at close proximity will not be effective if there is little continuity of supervision. Parental monitoring looks different in different situations, yet it is always represented by active efforts on the part of caregivers to protect children.

Measuring Parental Monitoring. Parental supervision has been measured in the literature via naturalistic observation, laboratory simulations and self-report measures. Each approach has advantages and disadvantages. Naturalistic observation provides a realistic portrayal of supervisor behaviors. Logistically, however, measuring supervision long enough to capture its relationship to low base rate phenomenon such as injuries or CSA victimization would be invasive, unethical, and require a great deal of resources. Another way to observe supervision is between parent and child pairs in laboratory settings with simulated hazards (Schwebel \& Kendrick, 2009). This method provides a clearer picture of parental behaviors in response to risks, but it is important to note that supervisors may be regulating their behavior in a socially desirable manner in response to observation, and the simulated situations may lack real world replicability. A final method of measurement is through the use of self-report measures or diary methods (Scwebel \& Kendrick, 2009). This approach can be administered while caregivers participate in simulated laboratory situations or they can be administered to caregivers following an event such as an injury (Saluja, Brenner, Morrongiello, Haynie, Rivera \& 
Cheng, 2004). Self-report and diary measures may be less subject to social desirability biases than observation in establishing supervisor behavior. Despite this strength, diary and self-report measures of parental monitoring have been criticized for tapping into what the parent knows about the child's whereabouts, rather than active tracking and checking on the child (Stattin \& Kerr, 2000; Racz \& Mcmahan, 2011). Each method of measuring parental monitoring is not without its limitations. Observation can require a great deal of resources, be invasive and subject to social desirability bias, and self-report measures can also elicit social desirability bias and fail to capture the true phenomenon. Despite these limitations, replicating measures of supervision across these methods and developing new methods of measurement can help researchers paint a suitable picture of effective monitoring.

One important aspect of measuring parental monitoring is risk perception (Saluja et al., 2004). Caregiver, child, and environmental characteristics have a bidirectional and complex relationship that together determine the risk perception of the caregiver. In order for studies to truly capture supervisor behaviors, it is imperative that they account for this complex relationship. The fact that caregiver over-protection is undesirable both further complicates risk perception, and lends support to the fact that ignoring the complexity and contextual factors influencing risk perception will result in distortions in our understanding of parental monitoring perception (Saluja et al., 2004). Findings suggest that accounting for risk perception and factors that influence risk perception is key to understanding monitoring behaviors.

Parental Monitoring Findings. Researchers have found parental monitoring to be associated with a number of child outcomes. In observational studies, verbal and physical 
strategies used to divert children away from danger have been associated with a reduction is child injuries (Saluja et al., 2004). It is likely, however, that these supervisory behaviors change across different contexts, and should be studied further in order to more fully determine the impacts of contexts on these behaviors (Saluja et al., 2004). Other studies relying on supervisor self-reporting have examined the role of parental monitoring in preventing child victimization, but results in this area have been inconsistent. Esbensen, Huizinga and Menard (1999) found parental monitoring to be a moderate negative predictor of child victimization. In contrast, Turner, Finkelhor \& Ormrod (2007) found parental monitoring to be a positive predictor of child victimization, perhaps due to the fact that child victimization leads to increases in parental monitoring in response to the original victimization. Overall, findings from parental monitoring studies indicate that it has potential as an area of prevention research, but methodological improvements are needed in order to better clarify the relationship between key variable of interest.

In conclusion, a thorough review of all literature relating to parental monitoring indicated that it is a concept related to many child outcomes, including CSA perpetration. Despite the wide acceptance of its importance, the protective features of parental monitoring are poorly understood. Better understanding the complexities of parental monitoring in different contexts is needed in order to effectively apply parental monitoring recommendations to intervention efforts.

“Guardianship" and Routine Activity Theory. Another way in which supervision can be defined is through "guardianship", which comes from the criminology literature and is part of Routine Activity Theory (RAT). As previously noted, RAT 
examines how every day routines contribute to risk and suggests that three key factors facilitate crime: (1) the presence of a suitable victim; (2) the presence of a motivated offender; and (3) a lack of supervision (Cohen \& Felson, 1979). Risk related to the third factor, a lack of supervision can, be mitigated using what RAT refers to as a "guardian." The following section will review how guardianship is defined, followed by an overview of how guardianship can overcome various common barriers to effectively monitoring children.

Defining "Guardianship". Guardianship is defined as the presence of any person who can deter a crime. According to Cohen and Felson (1995) there are two types of guardians who can prevent victimization. A "capable guardian" is a direct supervisor who has the ability to step in and prevent a crime from taking place, such as a parent. A "potential guardian," by contrast, is any individual who might not be acting as a supervisor, but whose mere presence may deter a crime from taking place. Introducing guardianship to account for "lack of supervision" can help to explain why crime takes place according to RAT.

Guardianship Findings. Despite being a core component in Cohen and Felson's (1986) original theory, lack of a potential guardian as a risk factor for crime has received less attention in the literature then the other two facets of RAT (e.g., the presence of a suitable victim and the presence of a motivated offender; Tewksebury, Mustaine \& Stengel, 2008). Further, studies that have examined guardianship roles in preventing crime have had inconclusive findings (Tewksebury, Mustaine \& Stengel, 2008; Tewksbury and Mustaine, 2003). One reason past studies have had inconclusive findings may be related to a lack of psychometrically sound measures. For example, a study that 
measured guardianship in terms of the presence of police and fire stations, number of "active block watches" and unemployment rates failed to find a relationship between guardianship and sexual offenses (Tewksebury, Mustaine \& Stengel, 2008). This brings into question why these particular measurements of guardianship were expected to have a measurable effect on sexual crime. Additional research is necessary in order to determine what variables related to guardianship may have protective factors, as well as what types of guardians, such as community members, parents or police officers, may better predict the perpetration of crime and their prevention.

Extending Guardianship. "Extending Guardianship" refers to ways in which supervision can increase past a primary supervisor to other forms of surveillance in the community. Criminological theory has found the strict control of adolescent behaviors by their parents to be ineffective as a prevention strategy due to the amount of time adolescents spend away from their parents (Well and Rankin, 1988). One way to more effectively address this issue is through the development of policies that extend guardianship to other responsible adults in public places and youth focused community organizations. For example, guardianship may be extended by: increasing formal surveillance with security cameras; making greater use of "place managers" such as security guards or crossing guards; reducing the anonymity of potential offenders by having community centers check IDs; increasing natural surveillance (e.g., moving a play area to a location that can be easily seen by supervisors); and creating policies that prevent children from interacting alone with other adults or older teens (Clarke, 2005; Felson, 1995). Youth Serving Organizations (e.g., Big Brothers and Big Sisters, YMCA) are important sources of extended guardianship for children where these policies can be 
implemented. Research suggests that despite offenders' skill at circumventing supervision to some extent, these strategies do provide a protective role in reducing risks related to child victimization. Nonetheless, there is still a great deal to be learned about the characteristics of guardianship that make it more or less effective in preventing CSA victimization.

In conclusion, "guardianship" provides another way in which supervision of children can be theoretically conceptualized. Accounting for guardianship helps to better describe crime risk according to RAT. Better understanding how and when guardianship is effective in deterring crime is an area that requires further research.

\section{A Critique of The Current Literature}

The previous sections detailed what we know about CSA offenders and their victims, as well as how the research literature has conceptualized child supervision practices to date. This current section will provide a critique of the literatures important to the study of CSA perpetration. Specifically, literatures regarding offender modus operandi, parental monitoring, and guardianship are imperative for understanding how supervision relates to CSA perpetration. This section will address measures and methods used thus far, research findings, and what research gaps have yet to be filled.

\section{Modus Operandi.}

Kaufman's Modus Operandi Questionnaire (MOQ) is a self-report measure that asks offenders to report the nature of the different sexual behaviors that they persuaded their victims to perform. The MOQ asks offenders to identify the frequency with which 
the used certain strategies in order to commit CSA on a Likert-type scale $(0=$ never; $3=$ almost always). This 339-item questionnaire is split into subsections chronologically (i.e., Gaining Victim Trust; Bribes and Enticements to Gain Victim Compliance, Threats to Gain Victim Compliance; and Keeping the Victim Quiet about Sexual Contact) in order to comprehensively assess the offenders' modus operandi throughout the course of the abuse. The MOQ has been used with both adolescent and adult offenders, and identifies behaviors throughout all stages of the CSA perpetration process. A particular strength of the self-report method utilized by the MOQ is that it has generally provided a greater amount of information than the structured interview version of the questionnaire (Kaufman, Hilliker, Lathrop, Daleiden, \& Rudy, 1996).

In addition to its many strengths, there are limitations associated with the MOQ as well. These limitations are due to the self-report and retrospective method of data collection, as well as the limited generalizability of its findings. First, the data collected is based on offender self-report and sample sizes in many studies have been small (Leclerc \& Felson, 2014; Leclerc, Proulx, McKibben, 2005). Despite the anonymity promised in MOQ studies, the sensitive nature of the information may have limited offender self-reporting. This may be especially true for certain behaviors that may not be known to the juvenile justice system, or behaviors that have not yet been disclosed in treatment. Another possible limitation associated with the MOQ is the retrospective nature of the self-reported data. Offenders may not be entirely accurate in their recall of events. The problem of recall is mitigated by the fact that the offenders who are studied are often engaged in treatment, which helps them gain perspective in regard to their crime (Kaufman et al., 1996). Furthermore, the administration of the MOQ is limited to 
convicted sexual offenders, and results generated from the measure may only be generalized to that population. Restricting studies to convicted offenders is not ideal, but it is necessary, due to the low level of disclosure typically associated with CSA perpetration. Furthermore, there would be practical, ethical and social desirability limitations to administering the MOQ to a more general population. Despite these limitations, the MOQ has shown to be a reliable and valid tool for better understanding the modus operandi of juvenile and adult sexual offenders.

\section{Parental Monitoring.}

There are a variety of measurements that have also been used to assess parental monitoring. Parental monitoring can prevent a number of negative outcomes, but a majority of the literature is related to child injury prevention (Saluja et al., 2004; Stattin \& Kerr, 2000). Parental monitoring has been defined as "a set of correlated parenting behaviors involving attention to and tracking of the child's whereabouts, activities, and adaptations" (Dishion \& McMahon, 1998, p. 61). When it comes to parental monitoring, methods vary a great deal across studies. Post event interviews contribute understanding of how lack of supervision contributes to injury, as do questionnaires that ask caregivers to report their supervision style (Saluja et al., 2004). Sometimes participants are sampled from the general population, such as observational studies in lab or naturalistic settings, but many other studies sample supervisors after an event such as an injury to the child has taken place (Saluja et al., 2004). Retrospective studies of injury and abuse are important to understanding parental monitoring, but studies of this nature are subject to sampling bias, such that parents with children who never suffer from an injury or abuse are never sampled. In recent years, study designs have expanded to include more variables 
associated with supervision that are related to the context of the behaviors (Saluja et al., 2004)

Despite the strengths associated with the assessments of parental monitoring, a number of limitations exist, as well. Areas of concern include lack of a reliable measurement, social desirability bias, and the highly situational nature of supervisory behaviors (Saluja et al., 2004; Schwebel \& Kendrick, 2009). First, some self-report measures have been criticized for measuring child disclosure rather than caregiver supervision (Schwebel \& Kendrick, 2009). This may be true of measurements that relate parental monitoring to antisocial behavior in adolescents. Studies of this nature suggest that strict controlling and monitoring of adolescents' behavior will reduce their levels of antisocial behaviors, but those studies should be interpreted with care, as they may not reflect actual, objective supervision (Schwebel \& Kendrick, 2009). Furthermore, the reports of parental monitoring are highly subject to social desirability bias since it is not typically socially acceptable for caregivers to provide poor supervision (Schwebel \& Kendrick, 2009). A final potential issue with measures of parental monitoring is the highly situational nature of supervisory behaviors. Research has thus far failed to capture which caregiver strategies are consistent across contexts. Further complicating this issue is the fact that parents may increase the number of supervision strategies they use in response to certain events such as an injury (Saluja et al., 2004). Fortunately, current directions in the child monitoring literature have accounted for methodological issues such as lack of reliable measurements (Saluja et al., 2004; Schwebel \& Kendrick, 2009). Future research on parental monitoring should examine behaviors across different types 
of measurements in different contexts as a means of establishing how supervision looks within an ecological framework (Schwebel \& Kendrick, 2009).

\section{Guardianship.}

There are certain strengths and weaknesses associated with studies pertaining to guardianship. As previously mentioned, guardianship is a term analogous to parental monitoring that describes how caregivers track their children. Guardianship is an important component of RAT, which relies on not only the child's primary supervisor as a deterrent for crime, but also the mere presence of other people, (e.g., "potential guardians') and strategies to include others in supervision (e.g., "extending guardianship"). Most guardianship studies are embedded in larger studies of RAT, but some studies have examined guardianship on its own. Studies have generally examined correlates between measures of guardianship (e.g., number of hospitals or police stations) and occurrences of crime (Tewksebury, Mustaine \& Stengel, 2008; Tewksbury \& Mustaine, 2003). Measurements of guardianship are very broadly defined as the presence of any person or strategy to increase supervision. As a result of these broad definitions, a valid and reliable measure of guardianship has yet to be established (Tewksebury, Mustaine \& Stengel, 2008; Tewksbury \& Mustaine, 2003). Not surprisingly, these questionable measures of guardianship have yielded inconsistent results. For instance, it is rather unsurprising that certain measurements of guardianship such as percentage of unemployed residents and living near a neighborhood watch sign do not have significant influences on crime rates (Tewksebury, Mustaine \& Stengel, 2008; Tewksbury \& Mustaine, 2003). 
There are several ways in which the study of guardianship can be improved upon. First, measures should be more specific and draw on a wider array of methods in order to determine which components of guardianship are most effective. For example, selfreports from caregivers and offenders could provide important information about effective guardianship. Guardianship should also be used as a compliment to parental monitoring. Current models of parental monitoring have evolved to account for personal characteristic, social and ecological factors that may influence supervision decisions. Guardianship and RAT, however, are longstanding concepts that should not be ignored in developing effective supervision practices. Better measures of guardianship can serve as a compliment to parental monitoring measures by accounting for potential and extended guardianship. These two important facets of guardianship may drive supervision in ways that are not always captured fully by parental monitoring measures.

\section{Current Research Findings.}

Research has effectively established distinguishing factors among groups of CSA offenders in their use of strategies across the modus operandi continuum. For instance, it is known that adolescent sex offenders use a greater number and frequency of modus operandi strategies than their adult counterparts to gain victim silence and compliance (Kaufman et al., 1998). Sex differences have also been established, with a majority of offenders being male and a majority of victims being female (Cortoni and Hanson 2005; Finkelhor, Ormrod \& Chaffin, 2009). Furthermore, important distinctions have been found in intra-versus extra familial offenders, with intra-familial offenders more likely to use gifts to gain victim's trust than extra-familial adolescent offenders who may be more likely to use drugs and alcohol to gain compliance in their victim (Kaufman et al., 1996). 
Differences based on victim age reveal that juveniles with older victims tend to use more force or violence (Aebi, Vogt, Plattner, Steinhausen, \& Bessler, 2012; Fanniff \& Kolko, 2012). Despite these important findings, there are additional critical distinctions related to sexual offenders' modus operandi strategies that are yet to be identified.

Thus far, parental monitoring has been only loosely related to CSA perpetration. For instance, children who are left unattended have been found to be targets for abuse (Elliot, Browne \& Kilcoyne, 1995). Further contributing to the idea that parental monitoring is important to CSA prevention is the fact that particular parent characteristics have also been linked to an increased risk of child sexual abuse. Examples include less formal education, greater amounts of absenteeism from the home, single mother households and parental substance use (Bagley, Thurston \& Tutty, 2006; Walsh, MacMillan, \& Jamieson, 2003). Interventions could certainty be targeted around children who are exposed to these characteristic parent risk factors, however better elucidating the nature of these relationships may reveal a variety of more effective directions for CSA prevention and intervention (Bagley, Thurston \& Tutty, 2006; Walsh, MacMillan, \& Jamieson, 2003).

The literature on Routine Activity Theory (RAT) reflects another important area that may have significant implications for enhancing CSA efforts. A strength of RAT over Parental Monitoring theory is that it accounts for typical barriers that arise when it comes to providing effective supervision for a child or adolescent. Parents are important sources of guardianship, but even in the best of circumstances, their direct supervision is not consistent over time (Demo, 1992; Well and Rankin, 1988). Moreover, as children grow older, they are more likely to be trusted to be on their own and left without direct 
supervision (Schwebel et al., 2011). RAT accounts for other forms of supervision, however better measures are needed in order to establish which types of guardianship are most effective in preventing CSA. One study that measured guardianship as proximity to police and fire stations, number of "active block watches," and unemployment rates failed to find a relationship between guardianship and sexual offenses (Tewksebury, Mustaine \& Stengel, 2008). This may be due to the fact that those particular measures do not reflect true levels of guardianship. Thus far, measures of parental monitoring and guardianship have been somewhat limited, and neither has directly addressed risks associated with the use of babysitters or temporary supervisors as guardians.

The existing literature, which focuses on modus operandi of sexual offenders, parental monitoring, and RAT, has begun to provide a framework for effective prevention of CSA. However, it is clear that gaps still exist related to subgroups of offenders, measurements of parental monitoring and guardianship, and the relationship between CSA and offender modus operandi.

\section{Purpose of the Present Study.}

The purpose of the present study is to determine how strategies used by JSOs to commit CSA differ according to their supervisory status. It's likely that factors related to JSO efforts, parents' need for child care assistance, and factors that interfere with parents' ability to adequately care for their children all contribute to the chances of a JSO being placed in the role supervisor for a child. It also follows that the supervisory role affords the juvenile a certain degree of status and power that likely translates into a diminished need to use modus operandi strategies to involve children in the process that leads up to sexual abuse (e.g., as compared to JSOs who are not in a supervisory role). At 
the same time, it is likely that characteristics of the JSO, their victim, and the victim's parent (i.e., regarding their availability to supervise) will impact supervision in such a way that the JSOs' use of various manipulative and coercive modus operandi strategies are altered as they proceed toward their goal of offending against the child in their care. Findings associated with supervision and its relationship to a JSOs choice of modus operandi strategies has implications for prevention within a Routine Activities Theory. This study will also expand on measures of parental monitoring and guardianship through the use of a unique measure of supervision drawing from offender reports. A clear theme in both the parental monitoring and RAT literature is that "adequate supervision" often looks different based on the developmental stage of the child and on other significant contextual factors such as the supervisor's perception of risk (Leclerc, Smallbone \& Wortley, 2013; Racz \& Mcmahan, 2011; Saluja et al., 2004; Stattin \& Kerr, 2000). Improving upon this research will help to determine how caregiver supervision can protect against negative child outcomes in differing contexts (e.g., a parent supervising multiple children at home versus a parent watching one child play at the park). 


\section{Research Questions}

\section{Becoming a Supervisor}

Research Question One (RQ1; Figure 2): Which factors related to perpetrators' efforts, parents' need for child care assistance, and factors that interfere with parents' ability to adequately care for their children (e.g., referred to here as "parental disruptors") will significantly contribute to the prediction of which JSOs will become a child victim's supervisor?

No known study to date has examined how JSO's become supervisors to their victim. It is likely that JSO's efforts, parents' need for child care assistance, and factors that interfere with parents' ability to adequately care for their children all contribute to the likelihood of a JSOs being placed in the role of a child's supervisor.

Hypothesis 1a (H1a): Perpetrators' efforts to get the child alone, parents' need for child care assistance, and parental disruptors will all be significantly related to becoming a supervisor to the child.

Hypothesis 1b (H1b): Perpetrators' efforts to get the child alone, parents' need for child care assistance, and parental disruptors will each contribute significant unique variance in the prediction of which juveniles will become a supervisor to a child.

\section{Strategic Grooming}

Research Question 2 (RQ2; Figure 3): Does the act of serving in a supervisory role to their future victim reduce the JSO's need to use more "strategic" grooming strategies?

Past research has found that JSOs tend to engage in more frequent use of modus operandi strategies compared to their adult counterparts, perhaps due to a lack of access 
to resources, and the fact that they lack a certain implicit authority that adults hold, and thus have to do more work to gain victim compliance (Kaufman et al., 1998). Research has not yet examined whether or not this implicit authority is present in adolescents who are trusted by parents as babysitters or temporary supervisors in a way that influences their use of modus operandi strategies.

Hypothesis 2a (H2a): JSOs who served in a supervisory role to their victim will use significantly fewer modus operandi strategies overall to gain their victim's trust, to gain victim cooperation, and to maintain their silence compared to JSOs who did not serve as a supervisor.

Hypothesis $2 \mathrm{~b}(\mathrm{H} 2 \mathrm{~b})$ : JSOs who served in a supervisory role to their victim will use significantly fewer threats to gain victim compliance as compared to JSOs who did not supervise their victim.

Hypothesis 2c (H2c): JSOs who served in a supervisory role to their victim will use significantly more bribes and enticements to gain victim compliance than JSOs who were non-supervisors.

\section{Factors that moderate strategic grooming}

Research Question 3 (RQ3; Figure 4): What perpetrator, victim, and victim caregiver factors moderate the relationship between supervision and JSOs' use of modus operandi strategies?

Research has found JSOs to be a heterogeneous group (Fanniff \& Kolko, 2012), and as such, several factors are expected to moderate the use of modus operandi strategies. These potential moderators include age and number of previous victims. For 
example, older JSOs and those with more victims may be more similar to adult offenders due to their higher level of interpersonal skills and sophistication (Kaufman et al., 1996; Leclerc, Proulx, \& Beauregard, 2009). Studies examining victimization differences between males and females have found that males are more likely to experience intrusive forms of abuse (e.g., oral and anal abuse), and more likely to experience threats (KendallTackett \& Simon 1992; Ketring \& Feinauer, 1999). Studies have also found that JSOs with older victims may be more likely to use threats or violence than those with younger victims (Aebi et al., 2012; Fanniff \& Kolko, 2012), as well as more manipulative modus operandi strategies (Leclerc, Carpentier \& Proulx, 2006). Furthermore, Routine Activity Theory suggests that a lack of supervision is necessary for a crime such as CSA to take place (Cohen \& Felson, 1979). While JSOs who act as supervisors are able to circumvent that supervision, those who are not likely have to use various strategies, such as the use of threats, to gain access to their victim.

Hypothesis 3a (H3a): The relationship between JSO supervision and strategic grooming will be moderated by key JSO characteristics (e.g., age, number of previous victims). For JSO supervisors there will not be a moderating effect for either variable since these youths will already have considerable status and power as a supervisor empowered by the child's parent. In contrast, there will be a significant moderating effect for both variables (i.e., age, number of previous victims) with youth who were not supervisors. Increased age and more previous victims will be associated with less strategic grooming (i.e., the use of fewer strategies across the four modus operandi categories: gaining victim trust, bribes and enticements to gain victim compliance, threats to gain victim compliance, and keeping the victim quiet about sexual contact). 
Hypothesis $3 b(\mathrm{H} 3 b)$ : The relationship between JSO supervision and use of strategic grooming strategies will be significantly moderated by key victim characteristics (e.g., age, gender). For both JSOs who supervised and those who did not, there will be a moderating effect of both variables such that JSOs will use more modus operandi strategies with both older and male victims.

Hypothesis 3c (H3c): The relationship between supervision and the use of modus operandi strategies will be significantly moderated by “disruptors" in victim's parents' lives (e.g., working too many hours, too many other family members to care for, trying to keep a marital or dating relationship, the child was visiting with his/her other parent, the parent was suffering from emotional problems, the parent was suffering from physical/health problems, the parent was suffering from domestic violence, the parent was using drugs and/or alcohol). For JSO supervisors there will not be a moderating effect for disruptions to supervision since these youths will already have considerable status and power as a supervisor empowered by the child's parent. In contrast, there will be a significant moderating effect for disruptions to supervision with youth who were not supervisors. Each of the disruptors will be associated with a significant drop in strategic grooming (i.e., the frequency of strategies used across the four modus operandi areas). 


\section{Methods}

\section{Participants}

The current study is part of a larger, ongoing investigation by Dr. Keith Kaufman and his colleagues on sex offenders' patterns of perpetration (e.g., "modus operandi”) and the impact of parental supervision on offending behavior (supported by CDC Grant R49/CCR016517-01). The original subsample consisted of 854 offenders, 370 of who were juvenile sexual offenders (JSOs), who will be the focus of this study.

JSOs were recruited from offender facilities located in Florida, Oregon, New York and South Carolina. Seventy-four percent of the sample $(n=248)$ reported being a student as their primary job before they were incarcerated. The average age those participants reported first abusing a child was 11.36 years old $(S D=8.23)$. Forty-eight percent of the sample $(n=163)$ reported that they lived with or were related to their victim(s), whereas $50.7 \%$ of the sample $(n=171)$ reported at least one extra-familial victim.

\section{Design}

This study used a cross-sectional, non-experimental design. Participants completed all questionnaires at one time and were sampled once during the course of the study. This study is examining relationships between modus operandi and victim supervision as reported by juvenile sex offenders.

\section{Descriptions and Measurement of Study Constructs}

Modus Operandi. Modus Operandi was assessed via responses to the Adolescent Modus Operandi Questionnaire (AMOQ), which was administered as a part of the larger 
study (Kaufman et al., 1994, 1996). This 369-item self-report questionnaire was developed drawing on input from offenders, victims, and professionals in fields such as law enforcement, victim treatment, and offender treatment (Kaufman et al., 1998). The questionnaire asks sex offenders to identify the frequency with which they used certain strategies $(0=$ never, $3=$ almost always $)$ in order to commit CSA across the continuum from accessing potential victims through maintaining victim silence once abuse has begun. The current study examines four content areas of the AMOQ, presented in Figure 5, that were developed using exploratory factor analysis. The AMOQ sections include: (1) Gaining Victim Trust; (2) Gaining Victim Cooperation; (3) Threats to Get the Victim Involved in Sexual Activity; and (4) Keeping the Victim Quiet About Sexual Abuse.

Mean subscale scores for each participant were calculated from these items for the purpose of this study. In order to account for missed items, subscales were only calculated for cases in which the participant responded to at least half of the items in that subscale. An overall mean score defined as strategic grooming was computed across the four subscales, consistent with Kaufman et al.'s (1998) measurement of overall modus operandi. The overall mean score demonstrated excellent reliability, with a Cronbach's alpha of $.98 \alpha$. Individual items for each of the AMOQ subscales and internal reliability for those subscales are presented in Table 1.

Previous studies investigating the reliability and validity of the AMOQ questionnaire have found the internal consistency of the AMOQ scales to be good to excellent with adolescent offenders (Cronbach's alpha ranged from $.80 \alpha$ to $.95 \alpha$, Kaufman, Hilliker \& Daleiden, 1996). The validity of the AMOQ has been supported through a comparison of structured interview and self-report methods (Kaufman, Hilliker 
\& Daleiden, 1996) as well as group differences between adult and juvenile sexual offenders and intra- and extra-familial child sexual abuse (Kaufman et al., 1998).

Victim Supervision. Victim supervision was assessed using the Supervision Questionnaire (SQ; Kaufman, 2001). The SQ was designed for the original larger CDC study and included multiple self-report subscales assessing victim supervision as reported by the juvenile offender. For this study, supervisor status is assessed with the question "Put a check on the line next to the people that were responsible for knowing where the child was during any of the times that you were abusing him/her" where JSOs marked the line "I was the supervisor". Supervision Questionnaire subscales and their internal consistency are presented in Table 2, and include efforts to get the child alone (e.g., "offering to babysit the child"), parents' need for child care assistance (e.g., "asking the juvenile to babysit"), and parental disruptors (e.g., "S/he was trying to keep a marital or dating relationship"). Participants responded to each item on a Likert scale ranging from 0 (never) to 4 (always).

\section{Procedures}

IRB approval for the study was obtained from Portland State University prior to data collection. Juvenile sex offender (JSO) participants were recruited from juvenile correctional facilities in four states (e.g., Florida, Oregon, New York and South Carolina). JSOs provided assent using a form, which was read aloud to them, in addition to consent that was provided by representatives of state facilities who have custody of adolescents. All responses were anonymous and participation was voluntary. Next, participants were screened for reading level, comprehension abilities, and significant mental disabilities. Eligible participants were given three paper and pencil questionnaires: 
the Demographic Questionnaire (Kaufman, 2001), the Supervision Questionnaire (SQ; Kaufman, 2001), and the Adolescent Modus Operandi Questionnaire (AMOQ; Kaufman, 1994). Participants typically took between 45 and 60 minutes to complete the Demographic Questionnaire and the SQ, and approximately 40 minutes to complete the AMOQ. A research assistant remained on hand to ensure that participants answered all survey questions. The research assistant then collected the completed questionnaire packets and returned them to Portland State University where they remain secured in a locked file cabinet. 


\section{Results}

\section{Exclusion Criteria}

Several variables collected via the Demographics Questionnaire were used to establish the final sample for the study. Offenders who did not commit a sexual offense before the age of $18(n=10)$ were excluded from the analyses, as were offenders who did not report victims under the age of $12(n=2)$, female offenders $(n=11)$, and offenders who completed their measures in Spanish $(n=9)$. This resulted in a final sample of 337 offenders between the ages of 11 and $23(M=16.71, S D=2.23)$ when they completed the measure, with self-reported ethnic identities of Asian American $(n=3)$, African American $(n=37)$, European American $(n=189)$, Latino $(n=30)$, Native American $(n$ $=11)$ and Mixed ethnicity $(n=66) .213$ participants $(63.2 \%)$ reported having at least one male victim. Offenders reported having an average of 5.63 victims $(S D=7.51)$, with the average age of the last child they abused as $7.53(S D=3.47)$ years of age. Forty-three (43) participants reported having only male victims, 119 (35\%) participants reported having only female victims, and 170 (50\%) participants reported having a mix of both male and female victims.

\section{Preliminary Analysis}

To begin, a series of preliminary analyses were run in order to test whether the data meets the assumptions required for linear regression analyses. Examination of the data did not point to any outliers. Tests of skew and kurtosis did reveal a strong positive skew in the dependent variables. A series of transformations was initially considered, however non-linear transformations would lead to reductions in variance, which would ultimately make subtle differences difficult to detect. Despite the strong skew, Central 
Limits Theorem argues that large sample sizes serve as a protective factor for false results due to distribution. In other words, the low base rate responses in our sample may in fact reflect that these are simply low base-rate behaviors in the general population of JSOs.

Next, the data was examined for missing items. Sub-scale scores that were not calculated for the AMOQ due to missing items accounted for less than $2 \%$ of the data. JSOs who did not report the age of their last victim or disruptions to the victim's parents' supervision accounted for a slightly higher percentage of missing data (i.e., $4 \%$ ) however a series of chi-square tests revealed that those JSOs did not differ significantly from JSOs who were included in the analyses on their strategic grooming score. This was true for both age of last victim $\left(\chi^{2}(303, \mathrm{~N}=337)=303.15, p=0.454\right)$ and disruptions to the victim's parents' supervision $\left(\chi^{2}(303, \mathrm{~N}=337)=279.99, p=0.824\right)$.

A series of regression analyses were conducted in order to test whether certain covariates should be included in the final analyses. Past literature suggested that both length of treatment and state of data collection may be related to our outcomes of interest, however neither of these variables were significantly related to any of the outcome measures, and thus were excluded from further analyses.

\section{Inferential Analysis}

A series of regression analyses were conducted to test the proposed hypotheses. For RQ1, logistic regressions were used. Predictors included perpetrators' efforts to get the child alone $(M=.77, S D=.81)$, parents' need for child care assistance $(M=1.56, S D$ $=.85)$, and disruptions to supervision $(M=.74, S D=.70)$. The outcome variable was whether or not the offender reported acting as a supervisor at any time while offending against their victim (i.e., with $1=$ yes $[n=83]$ and $0=$ no $[n=254])$. For RQ2 and RQ3, 
standard regressions were used. Whether the JSO reported acting as a supervisor was treated as the independent variable. Outcomes for RQ2 included bribes to gain victim compliance and related subscales, threats to gain victim compliance and related subscales, as well as strategic grooming (see Table 1). RQ3 examined whether JSO age, number of victims, victim age, victim gender, or disruptions to victim supervision moderate the relationship between acting as a supervisor and outcomes including strategic grooming, threats to gain compliance, and bribes to gain compliance. Since none of the proposed covariates were found to be significantly related to the outcome variables, they were removed from the analyses. For the analyses in which moderated regression was used, continuous variables were standardized then centered prior to the analyses in order to ease interpretation of the results.

Hypothesis 1a (H1a): Perpetrators' efforts to get the child alone, parents' need for child care assistance, and parental disruptors will all be significantly related to becoming a supervisor to the child.

Perpetrators efforts to get the child alone were significantly related to the log odds of acting as a child's supervisor, $\chi^{2}(1)=11.10, p=.001$, Cox-Snell $R^{2}=.033$. Each onepoint increase in efforts to get the child alone was associated with a 3.67 times greater chance that the JSO would be the child's supervisor. Parents' need for childcare assistance was also significantly related to JSO supervisor status. Each one-point increase in parents' need for childcare assistance was associated with a 1.65 times greater chance of JSO being a supervisor, $\chi^{2}(1)=58.33, p=.000$, Cox-Snell $R^{2}=.16$. Disruptions to supervision were not significantly related to the log odds of acting as a child's supervisor, $\chi^{2}(1)=.98, p=.318$, Cox-Snell $R^{2}=.003$. A one-point increase in disruptions to 
supervision was only associated with a 1.20 increase in likelihood of JSO being the child's supervisor.

Hypothesis 1b (H1b): Perpetrators' efforts to get the child alone, parents' need for child care assistance, and parental disruptors will each contribute significant unique variance in the prediction of which juveniles will become a supervisor to a child.

The three predictors together were significantly related to the log odds of acting as a child's supervisor, $\chi^{2}(3)=56.03, p=.000$, Cox-Snell $R^{2}=.159$. Controlling for the other variables, however, only parental need for childcare assistance significantly predicted the outcome variable. Specifically, controlling for the other variables, parents' need for childcare assistance positively predicts the log odds of acting as a child's supervisor, slope $=1.28$, Wald $\chi^{2}$ statistic $=37.55, p=.00$. Controlling for the other variables, perpetrators efforts to get the child alone fails to predict the log odds of acting as a child's supervisor, slope $=.07$, Wald $\chi^{2}$ statistic $=.133, p=.72$, as do disruptions to supervision, slope $=-.159$, Wald $\chi^{2}$ statistic $=.592, p=.44$.

Hypothesis 2a (H2a): JSOs who served in a supervisory role to their victim will use significantly fewer modus operandi strategies overall (i.e. less strategic grooming) to gain their victim's trust, to gain victim cooperation, and to maintain their silence compared to JSOs who did not serve as a supervisor.

Supervisor status explained a significant proportion of variation in strategic grooming $\left(\mathrm{R}^{2}=.02, F(1,333)=5.97, p=.02 ;\right.$ Figure 6$)$, however the directionality was opposite of what was predicted, with JSO supervisors using modus operandi more frequently than their non-supervising counterparts. 
Hypothesis 2b (H2b): JSOs who served in a supervisory role to their victim will use significantly fewer threats to gain victim compliance as compared to JSOs who did not supervise their victim.

Supervisor status did not explain a significant proportion of variation in threats to gain compliance $\left(\mathrm{R}^{2}=.00, F(1,333)=.03, p=.87\right)$, nor did it predict any of the subscales within this category: threats to harm others $\left(\mathrm{R}^{2}=.00, F(1,333)=1.13, p=\right.$ $.29)$, use of a weapon $\left(\mathrm{R}^{2}=.00, F(1,333)=2.43, p=.12\right)$, making the victim feel helpless $\left(\mathrm{R}^{2}=.01, F(1,333)=3.08, p=.08\right)$, or psychopathy $\left(\mathrm{R}^{2}=.00, F(1,333)=1.20\right.$, $p=.27)$.

Hypothesis 2c (H2c): JSOs who served in a supervisory role to their victim will use significantly more bribes and enticements to gain victim compliance than JSOs who were non-supervisors.

Supervisor status did explain a significant proportion of variation in bribes to gain victim compliance $\left(\mathrm{R}^{2}=.01, F(1,333)=5.51, p=.02\right.$; Figure 7$)$, such that JSO supervisors reported using more of these strategies than their non-supervising JSO counterparts. Upon further analysis, supervisor status significantly predicted two of the subscales within this category: desensitizing the victim to sexual contact $\left(\mathrm{R}^{2}=.02, F(1\right.$, $332)=6.97, p=.01)$ and giving gifts and privileges $\left(\mathrm{R}^{2}=.04, F(1,329)=14.43, p=\right.$ .00). Supervisor status did not significantly predict the remaining four subscales: buying the victim clothing $\left(\mathrm{R}^{2}=.00, F(1,332)=.04, p=.85\right)$, drugs and alcohol $\left(\mathrm{R}^{2}=.00, F(1\right.$, $328)=1.68, p=.20)$, exposure to pornography $\left(\mathrm{R}^{2}=.00, F(1,332)=.12, p=.73\right)$, and engagement in pornography $\left(\mathrm{R}^{2}=.00, F(1,333)=.20, p=.65\right)$. 
Hypothesis 3a (H3a): The relationship between JSO supervision and strategic grooming will be moderated by key JSO characteristics (i.e., age, number of previous victims). For JSO supervisors there will not be a moderating effect since these youths will already have considerable status and power as a supervisor empowered by the child's parent. In contrast, there will be a significant moderating effect of both variables (i.e., age, number of previous victims) for youth who were not supervisors. Increased age and more previous victims will be associated with less strategic grooming (i.e., the use of fewer strategies across the four modus operandi categories: gaining victim trust, bribes and enticements to gain victim compliance, threats to gain victim compliance, and keeping the victim quiet about sexual contact).

First, a regression analysis was conducted in order to determine the extent to which JSO age of first offense and acting as a JSO supervisor predicts strategic grooming. The model explained $2.1 \%$ of the variance in strategic grooming, $F(3,331)=$ $3.43, p=.02$. JSO supervisor status significantly predicted strategic grooming, $\mathrm{B}=.26$, $\mathrm{t}(331)=2.07, p=.05$, however neither offender age $(\mathrm{B}=.10, \mathrm{t}(331)=1.81, p=.11)$, nor the interaction term $(\mathrm{B}=.03, \mathrm{t}(331)=.13, p=.74)$ were significant predictors. Next, a regression analysis was conducted to determine whether number of previous victims and acting as a JSO supervisor predicts strategic grooming. This model explained $14.4 \%$ of the variance in strategic grooming, $F(3,317)=18.97, p=.00$. Both JSO supervisor status $(\mathrm{B}=.25, \mathrm{t}(317)=2.06, p=.04)$ and number of previous victims $(\mathrm{B}=.32, \mathrm{t}(317)=5.60$, $p=.00)$ significantly predicted strategic grooming, with the interaction term approaching significance, $\mathrm{B}=.27, \mathrm{t}(317)=1.90, p=.06$. Number of previous victims is associated with more strategies for supervisors versus non-supervisors, opposite in direction from 
what was predicted in the original hypothesis. This moderated relationship is displayed in Figure 8.

Hypothesis 3b (H3b): The relationship between JSO supervision and use of strategic grooming strategies will be significantly moderated by key victim characteristics (e.g., age, gender). For both JSOs who supervised and those who did not, there will be a moderating effect of both variables such that JSOs will use more modus operandi strategies with both older and male victims.

First, a regression analysis was run to determine whether JSO supervisor status and age of the last child abused predict strategic grooming. This model was not significant, $\mathrm{R}^{2}=.01, F(3,220)=1.63, p=.18$. In order to examine the effect of victim gender and JSO supervisor status on strategic grooming, three regression analyses were conducted. First, a regression analysis was conducted to see whether JSO supervisor status and having only male victims predicts strategic grooming. This model explained $2.2 \%$ of the variance in strategic grooming, $F(3,327)=3.42, p=.02$. When controlling for the other variables, neither supervisor status $(\mathrm{B}=.23, \mathrm{t}(327)=1.72, p=.09)$, having only male victims $(\mathrm{B}=-.34, \mathrm{t}(327)=-1.92, p=.06)$, nor the interaction term $(\mathrm{B}=.68$, $\mathrm{t}(327)=1.56, p=.12)$ were significant predictors. Next, the same model was run with female only victims. This model accounted for $1.4 \%$ of the variance in strategic grooming, $F(3,330)=2.54, p=.06$. When controlling for the other variables, JSO supervisor status $(\mathrm{B}=.40 \mathrm{t}(330)=2.56, p=.01)$ was a significant predictor, while having only female victims $(\mathrm{B}=-.02, \mathrm{t}(330)=-.17, p=.87)$ and interaction term $(\mathrm{B}=. \mathrm{t}(330)=-$ $.27, p=.32$ ) were not. Finally, the regression was run using mixed gender versus single gender victims as the interaction term. This model explained $1.7 \%$ of the variance in 
strategic grooming, $F(3,330)=2.94, p=.03$. When controlling for the other terms, neither supervisor status $(\mathrm{B}=.32, \mathrm{t}(330)=1.73, p=.08)$, having mixed gender victims $(\mathrm{B}=.19, \mathrm{t}(330)=1.52, p=.13)$, nor the interaction term $(\mathrm{B}=-.04, \mathrm{t}(330)=-.17, p=.86)$ were significant predictors.

Hypothesis 3c (H3c): The relationship between supervision and the use of modus operandi strategies will be significantly moderated by "disruptors" in victim's parents' lives, measured here as the composite score of a 8-item scale (e.g., working too many hours, too many other family members to care for, trying to keep a marital or dating relationship, the child was visiting with his/her other parent, the parent was suffering from emotional problems, the parent was suffering from physical/health problems, the parent was suffering from domestic violence, the parent was using drugs and/or alcohol). For JSO supervisors there will not be a moderating effect for disruptions to supervision since these youths will already have considerable status and power as a supervisor empowered by the child's parent. In contrast, there will be a significant moderating effect for disruptions to supervision with youth who were not supervisors. Each of the disruptors will be associated with a significant drop in strategic grooming (i.e., the frequency of strategies used across the four modus operandi areas).

A regression analysis was conducted to examine whether JSO supervisor status and disruptions to primary supervision predicts strategic grooming. This model explained $4.6 \%$ of the variance in strategic grooming, $F(3,320)=6.19, p=.00$. When controlling for other variables, JSO supervisor status $(\mathrm{B}=.27, \mathrm{t}(320)=2.17, p=.03)$ and disruptions to parental supervision $(\mathrm{B}=.18, \mathrm{t}(320)=2.96, p=.00)$ were significant predictors, but the interaction term was not significant $(\mathrm{B}=.07, \mathrm{t}(320)=.47, p=.63)$. 


\section{Discussion}

The purpose of the present study is to determine how strategies used by JSOs to commit CSA differ according to their supervisory status. It investigates factors related to JSO efforts, parents' need for child care assistance, and factors that interfere with parents' ability to adequately care for their children, all of which contribute to the chances of a JSO being placed in the role of a child's supervisor. It also investigates whether holding a supervisory role is associated with the use of less strategic grooming strategies, as well as how certain victim, JSO, and victim parent characteristics moderate this relationship.

The data supports the hypothesis that perpetrators' efforts, parents' need for childcare assistance, and parental disrupters, significantly contribute to the prediction of which JSOs become a child's supervisor (i.e., H1a). It partially supports the hypothesis that each of those factors would contribute unique and significant variance to becoming a supervisor (i.e., H1b), with parental need for childcare assistance acting as the only significant predictor when controlling for the other two factors (i.e., perpetrators efforts and parental disruptors).

Further, the data did not support the hypothesis that JSOs who were in a supervisory role use less strategic grooming than those who did not serve as supervisors (i.e., H2a). Conversely, the data showed that JSOs who held supervisor roles used MO strategies significantly more frequently than JSO non-supervisors. No significant differences were found between JSO supervisors and non-supervisors on the threats and coercion scale or any of its associated subscales (i.e., H2b). JSO supervisors were found to use significantly more, not less, bribes and enticements to gain victim compliance 
compared to non-supervisors (i.e., H2c). Specifically, JSO supervisors tended to desensitize their victims to sexual contact, as well as give gifts and privileges more often than their non-supervisor counterparts.

JSO characteristics (i.e., age of first offence and number of victims) did not moderate the relationship between JSO supervision status and strategic grooming (H3a). The interaction between supervisor status and number of previous victims approached significance $(p=.06)$, however, increased number of victims was associated with more strategic grooming for supervisors rather than non-supervisors, as expected. The interactions between JSO supervisor status and victim characteristics (i.e., victim age and gender; H3b) did not significantly predict strategic grooming, nor did the interaction between JSO supervisor status and disruptions to supervision (i.e., H3c).

\section{Becoming a Supervisor}

The first research hypothesis examined which factors related to perpetrators' efforts to get the child alone, parents' need for childcare assistance, and parental disrupters, that significantly contribute to the prediction of which JSOs become a child's supervisor (i.e., H1a). These results have important implications for both the Routine Activity and Child Sexual Abuse (CSA) literatures, as they provide evidence for a relationship that has not yet been tested in either literature. Thus far, studies investigating guardianship have distinguished between "capable guardians" such as parents or primary supervisors, and "potential guardians," who are any individual whose presence might deter a crime (Cohen \& Felson, 1979; Felson, 1995). These distinctions, however, fail to capture the distinct qualities of babysitters or temporary supervisors, who parents trust to 
intervene for the safety of their child, but who may or may not be "capable" or trustworthy. Findings from H1a also offer an important contribution to the parental monitoring literature, which has called for the study of supervision in a wider variety of contexts using a broader range of methodologies (Racz \& Mcmahan, 2011; Saluja et al., 2004; Schwebel \& Kendrick, 2009; Stattin \& Kerr, 2000; Tewksebury, Mustaine \& Stengel, 2008).

Furthermore, these results have important implications for CSA prevention. For instance, the results of $\mathrm{H}$ la suggest that disruptions to supervision, such as a parent having too many other family members to care for or suffering from domestic abuse, do not relate to whether or not a JSO steps in as a supervisor. Perhaps in the case of distracted parents, the JSO did not have to step into a supervisory role as a means to sexually abuse, since the child was already vulnerable to abuse based on their parents' characteristics (Bagley, Thurston \& Tutty, 2006; Walsh, MacMillan, \& Jamieson, 2003). It is unclear from this particular study whether certain qualities of parental supervision mediate the relationship between parental characteristics and CSA. Future studies should examine whether offenders chose victims of "at-risk" parents due to the fact that the parent is simply too distracted to provide quality supervision that will prevent the abuse, or for other reasons (Schwebel \& Kendrick, 2009). For instance, children with "distracted" parents may be more likely to be exposed to potential offenders, or more likely to seek attention from strangers (Cohen \& Felson, 1979; Elliott, Browne \& Kilcoyne, 1995). Better understanding what puts these vulnerable children at risk will help highly distracted parents with restricted resources target their limited attention in directions that have the most preventive impact. 
These results also point to the limited value of only targeting parents who exhibit a narrow band of risk related characteristics (e.g., working too many hours, suffering from mental illness) for prevention programming. It appears as though some parents may rely on adolescents for help with supervision from time to time whether or not routine distractions exist. Instead of targeting "at-risk" parents, prevention initiatives should take a more "universal" approach, inform all parents of the heightened risk of relying on adolescents who are not appropriately screened or adequately prepared for supervising their children. Of course, these parents can also be instructed in the use of more active supervisory strategies over adolescent babysitters (i.e., unannounced home visits) to increase the safety of using this particular type of childcare.

The finding from analysis of the second research hypothesis $(\mathrm{H} 2 \mathrm{~b})$ suggest that only parents' need for child care assistance predicts the supervisor status of a JSO when controlling for perpetrators' efforts to get the child alone and the presence of parental disruptors. While JSO's likely take advantage of multiple risk factors in order to perpetrate CSA as originally hypothesized (Cohen \& Felson, 1979; Finkelhor \& Baron, 1986), these results suggest that the simple need for childcare assistance drives whether a JSO becomes a supervisor above and beyond the JSOs efforts to assume that role. This may point to JSOs deciding to commit CSA based on opportunities provided to them as a supervisor rather than specifically seeking out a supervisory role in order to commit abuse. An alternative hypothesis is that JSOs who are seeking supervisory roles are actually targeting parents who have previously asked for childcare help. Previous research has found that adult sexual offenders target single mothers who are overworked and in need of childcare (Elliot, Browne \& Kilcoyne, 1995). Future research could help 
to elucidate whether this strategy extends to JSOs, as well, and what strategies may be effective in addressing this type of vulnerability.

Finally, these results have implications for offender intervention. Based on the results of $\mathrm{H} 1 \mathrm{a}$, certain JSOs do make specific efforts to gain the role of supervisor over their victim by offering to babysit or help with childcare. These particular offenders will likely require differential treatment compared to more opportunistic JSOs, including stricter supervision following treatment. Other JSOs, those who did not actively seek out a supervisor role, but were merely assigned that responsibility by the victim's parent, may not require as intensive a treatment regimen. Moreover, these JSOs may require less emphasis on addressing risk factors that have been typically associated with offenders drawn toward child sexual abuse (e.g., inappropriate sexual arousal and fantasies involving children; Seto \& Lalumiere, 2010). While these results suggest that some JSOs strategically offer to care for children as a precursor to committing CSA, more research is needed to determine which JSOs are most likely to make this decision prior to taking on childcare responsibilities and which are offending in a more opportunistic fashion. This will help treatment providers address the specific motivations, beliefs and cognitions that lead the JSOs in supervisory roles to commit CSA (Efta-Breitbach, \& Freeman, 2004; Zankman \& Bonomo, 2004).

These results are only first steps in understanding how parents may unwittingly select a JSO or a future JSO as a supervisor for their child. Further research investigating how JSOs groom their victim's families and take advantage of multiple risk factors to commit CSA could help alert parents to red flags that can be addressed before risks turn to abusive behaviors on the part of the adolescent supervisor (Cohen \& Felson, 2009; 
Elliot, Browne, Kilcoyne, 1995; Wortley \& Smallbone, 2006). Determining which risk factors are most salient for JSOs as they make a decision to commit CSA will provide insights as to how those factors should be prioritized in crafting prevention initiatives in response to risks related to juvenile sex offending.

\section{Strategic Grooming}

Hypotheses $\mathrm{H} 2 \mathrm{a}-\mathrm{H} 2 \mathrm{c}$ suggested that JSOs who served as a supervisor to their victim would use significantly fewer modus operandi strategies overall (i.e., H2a), significantly fewer threatening and coercive modus operandi strategies (i.e., H2b), and significantly more bribes and enticements to gain their victim's trust and cooperation (i.e., H2c) than JSOs who did not supervise their victim. The first two hypotheses were not supported by the data, but the results were nonetheless interesting. It seems that rather than rely on their supervisor status to commit CSA as predicted, JSO offenders actually tend to engage in more frequent use of modus operandi strategies compared to nonsupervising JSOs (H2a). This increase in strategic grooming may be due to the greater amount of time that a supervisor spends with a victim that allows the JSO and may even require the JSO to engage in a range of strategies (Cohen \& Felson, 1979; Leclerc, Wortley \& Smallbone, 2010). Kaufman and his colleagues (Kaufman et al., 1998) suggested that in contrast to adult CSA offenders, JSOs engaged in a larger number of MO strategies. They hypothesis that juvenile offenders had less inherent status as compared to adults and therefore needed to be more active in their use of MO strategies to complete the sexual offense and to maintain victim silence following the onset of the abuse. Alternatively, JSOs who engage in more strategic grooming may be more manipulative, or may appear more intelligent to parents, and as such may be more likely 
to be chosen as temporary supervisors. Overall, having status as a supervisor does not appear to reduce the frequency of modus operandi strategies in JSOs making them similar to adult offenders, but perhaps supervisor status instead lends credibility to the JSOs efforts to lure their victim, gain compliance in CSA, and maintain silence following abuse (Kaufman et al., 1998).

Despite the fact that JSO supervisors, as a group, used modus operandi behaviors at a higher rate than non-supervisors, it is interesting to note that there was a small subset of JSO non-supervisors who reported using modus operandi behaviors at rates higher than all other JSOs. This subset of offenders may warrant further investigation in order to determine why acting as a supervisor did not fit into their highly strategic use of modus operandi strategies. Perhaps JSOs who engage in such frequent use of modus operandi strategies appear untrustworthy to parents and are less likely to be trusted with a parent's children.

The fact that there were no significant differences in the threats and coercion MO scale could be a reflection of a number of factors $(\mathrm{H} 2 \mathrm{~b})$. Items on the threats and coercion scale were not endorsed highly overall by either group, and may be more subject to social desirability bias compared to some sections of the questionnaire (Kaufman, Hilliker \& Daleiden, 1996; Tan \& Grace, 2008). Alternatively, JSOs may simply be relying on more prosocial strategies (i.e., bribes and enticements) to commit abuse whenever possible (Kaufman, Hilliker \& Daleiden, 1996). For both JSO supervisors and JSO nonsupervisors, the most highly endorsed subcategory within the threats and coercion scale was "make the victim feel helpless." Perhaps some JSOs resort to this strategy due to the fact that they lack the implicit authority held by adults who commit CSA (Kaufman et al., 
1998). Other JSOs who resorted to more extreme forms of threats in coercion, like threatening to hurt the victim or those close to the victim, may represent a more aggressive sub-group of offenders that exists across JSO supervisors and JSO nonsupervisors. JSOs supervisors may be just as likely as non-supervisors to use threats, and some may even use their supervisor status to give credit to the threats and coercions they use to commit CSA. Overall, however, the lack of differences between JSOs who act as supervisors and those who do not may simply reflect the fact that aggressive MO represents low base-rate behaviors to begin with, and that JSOs, in general, are more likely to use pro-social strategies (Kaufman, Hilliker \& Daleiden, 1996).

JSO supervisors did tend to use more bribes and enticements, as hypothesized (H2c), particularly involving desensitizing the victim to sexual contact and giving victims gifts and privileges. Both supervisor JSOs and non-supervisor JSOs highly endorsed those two types of MO behaviors. At the same time, significant differences regarding supervisor status are not surprising given the access and authority bestowed upon JSO supervisors. Parents of children who sometimes rely on adolescents for supervision should be aware of behaviors in which the older child might be "overly touchy" or treat the younger child to gifts or privileges (Elliot, Browne \& Kilcoyne; Henggeler et al., 2009; Zankman, Scott \& Bonomo, 2004). Not all adolescent babysitters who engage in such behaviors will necessarily sexually offend against a child. However, parents should have clear rules and boundaries around physical touch and the types of privileges that they can offer the children in their care as a means of enhancing CAS prevention efforts (Elliot, Browne \& Kilcoyne, 1995; Henggeler et al., 2009; Zankman, Scott \& Bonomo, 2004). 
Together, these results expand on previously reported findings suggesting that JSOs tend to engage in more frequent use of modus operandi strategies compared to their adult counterparts (Kaufman et al., 1998). JSO supervisors may not have the skills and resources available to adult sexual offenders, however acting as a supervisor does appear to play an important role in JSO's modus operandi. This has implications for CSA prevention as well as offender treatment interventions. With regard to prevention, it is important to educate professionals and members of the public to recognize that offenders with less strategic or seemingly more pro-social grooming styles may go more easily undetected (Kaufman et al., 1998). If JSOs who supervise children are more likely to give gifts and privileges and desensitize their victim to sexual contact as part of the CSA grooming process, then these are specific behaviors for which parents should remain vigilant (Elliot, Browne \& Kilcoyne, 1995; Kaufman et al., 1998; Kaufman, Hayes \& Knox, 2012). In terms of JSO treatment implications, JSO supervisors as a subgroup of offenders may exhibit other distinct patterns of offending that require more specific treatment goals (e.g., the difference between JSOs who have used more prosocial versus more antisocial grooming strategies). Understanding the breadth of common CSA grooming patterns can also have important implications for both preventing and investigating reported cases of CSA (Kaufman, Hayes \& Knox, 2012; Wortley \& Smallbone 2006). Educating parents about these modus operandi patterns and empowering them to report early signs of grooming may be particularly effective for preventing CSA. 
Factors that moderate strategic grooming

Study findings indicate that the relationship between supervision and the use of modus operandi strategies is moderated by key JSO characteristics, including age and number of previous victims (i.e., H3a), as well as by key victim characteristics such as age and gender (i.e., H3b), and by “disruptors” in victim's parents' lives (i.e., H3c). Results in these areas offer the potential to build upon existing literature to further examine previously established relationships between characteristics of the JSO, their victim, and their use of specific grooming strategies. For example, research has found that older JSOs or those with more victims may use modus operandi strategies in a similar fashion as adult offenders, and that offenders with male and older victims may be more likely to experience threats (Aebi et al., 2012; Fanniff \& Kolko, 2012; Kaufman et al., 1996; Leclerc, Proulx, \& Beauregard, 2009; Kendall-Tackett \& Simon 1992; Ketring \& Feinauer, 1999). None of these relationships, however, has been investigated in the context of JSOs who supervise their victims. Consideration should be given in future studies to further exploring how serving as a supervisor to a child victim may be related to these key variables.

Hypothesis 3a, which examines the moderating effect of JSO age and number of victims on grooming strategies, was not supported by the data. Rational Choice Theory states that criminals develop increased professionalism for committing crimes over time (Cornish \& Clarke, 1986). The acquisition of skills and knowledge to commit crime may help explain why adults tend to rely on fewer modus operandi strategies for committing CSA than juvenile sex offenders (Kaufman et al., 1998). In this study, only supervisor status predicted strategic grooming (i.e., while controlling for age of onset of committing 
abuse and the interaction between JSO supervision and age of onset). There are a number of possible explanations for these results. Despite their age, older JSOs are still limited by financial restraints, less knowledge about the world, a developing brain, and have fewer skills compared to adult offenders (Kaufman et al., 1998). Also, when controlling for supervisor status, age may relate less strongly to access to the victim and opportunities to groom the victim.

Interestingly, in the moderated regression using the number of victims, the interaction between JSOs acting as a supervisor, and the number of previous victims the analysis neared significance ( $p=.06$; Figure 8 ), such that JSO supervisors who had more victims used modus operandi strategies more frequently than JSO non-supervisors with more victims. This could point to a subset of JSOs who seek out supervisory situations, have multiple victims, and are involved in ongoing efforts to identify potential victims and carry out CSA. In line with this interpretation, JSOs may be build a wider array of modus operandi strategies as they gain more experience offending, and they may gain more confidence in their ability to use those modus operandi strategies and not get caught. Alternatively, this could reflect an increase in access to victims and opportunities for grooming for JSO supervisors versus JSO non-supervisors. Additional research is warranted to examine whether JSOs who take on supervisory roles and have multiple victims represent a unique subtype of strategic offender or if they are simply reacting to the opportunities afforded by greater access to victims while involved in child care.

The proposed moderating effects of victim characteristics (i.e., age and gender) and JSO supervisor status on strategic grooming was not supported. The models using only male and mixed gender victims significantly predicted strategic grooming. However, 
neither the interaction terms, nor the victim characteristic main effects were significant in any of these analyses. As such it appears that JSO supervisors and non-supervisors do not exhibit differences in strategic grooming based upon their victim characteristics. This is surprising given findings in the literature that support a relationship between victim characteristics and offenders' modus operandi (Aebi et al., 2012; Fanniff \& Kolko, 2012; Kaufman et al, 1996; Leclerc, Proulx, \& Beauregard, 2009; Kendall-Tackett \& Simon 1992; Ketring \& Feinauer, 1999) Future research on the relationship between JSO supervisory status, victim characteristics, and specific types of grooming, such as threats to gain compliance in sexually abusive behaviors, may reveal important differences in JSO MO strategies that were not identified in the current study. It's possible that a more ethnically/racially or economically diverse sample of JSOs may reveal such differences.

Finally, an examination of the effects of parental “disrupters” on JSO's grooming strategies (H3c) sought to expand upon the Routine Activity Theory (RAT) literature by establishing how parental behaviors are associated with JSOs grooming (Cohen \& Felson, 1979). This hypothesis was not supported, however the main effects, JSO supervisor status $(p=.03)$ and disruptions to parental supervision $(p=.00)$ significantly predicted strategic grooming. It seems that for both JSO supervisors and JSO nonsupervisors, disruptions to parental supervision can serve as an opportunity for JSOs to engage in grooming. In other words, when JSOs perceive that their victim's parent has issues in their life that limit their attentiveness (i.e., drug and alcohol abuse, domestic abuse issues, too many other children to care for), they tend to use modus operandi strategies more frequently. This seems to suggest that these disruptors serve as a cue to JSOs that parent safety mechanisms that would otherwise be present may have been 
compromised creating a vulnerability. At the same time the disruptors may create "routine activities" on the part of the parent that make the perpetration of CSA more likely to succeed. For example, consider a parent whose mental health or substance abuse difficulties physically or cognitively make the them less vigilant or absent to supervise their child's interactions with an adolescent intent on abusing their child. With this in mind, parents who suffer from disruptions to their supervision may require a combination of prevention strategies (e.g., educated about a variety of modus operandi strategies that JSOs have the potential to use against their young children (Elliott, Browne \& Kilcoyne, 1995; Kaufman, Hayes \& Knox, 2012) and practical assistance to address the disruptor more directly.

A knowledge of the moderating factors discussed in this study can help serve as the foundation for a template, which could guide the development of more effective prevention strategies. For example, as noted above, parents who experience significant "disruptors" to their supervision may need to be on the lookout for grooming behaviors in any adolescents who spend time with their children. They may also need to get help to directly address these disruptors, such as drug and alcohol abuse treatment, mental health treatment, or access to safe and low cost afterschool programs or daycare for their children. These findings also have practical implications for JSO treatment interventions. Establishing which factors moderate these relationships between the JSO and their grooming strategies can help paint a clearer picture of which offending subtype is most closely associated with a particular offender's constellation of modus operandi behaviors. Information of this nature can be used to create more tailored treatment plans for JSOs to ensure that they receive the help they require and that underlying issues which may be 
related to differential patterns of offending are adequately addressed (Efta-Breitbach, \& Freeman, 2004; Zankman \& Bonomo, 2004).

\section{Limitations}

There are a number of limitations associated with the present study. First, data is based on self-report by the JSOs. Despite the anonymity provided by the study, responses may be limited due to the sensitive nature of the questions. Even though the JSOs were already incarcerated for their crimes, some of the questions asked for details surrounding other crimes that may not have been disclosed. Another factor that could have potentially influenced responses was the length of the questionnaires (Galesic, \& Bosnjak, 2009). Participants may have experienced fatigue that negatively influenced the thoughtfulness of their responses. At the same time, however, participants were offered a snack, as well as a break in order to prevent this from happening. The retrospective method of data collection might have affected participant responses. The fact that offenders were engaged in treatment should, however, increase the likelihood that they had discussed and were relatively clear about the details of their crime(s) (Kaufman et al., 1996). There are other questions for which JSOs may have lacked the knowledge to accurately respond. For instance, income is usually an important covariate to include for the prediction of modus operandi strategies, but in this case, the relationship was not significant. This may be because adolescents had no knowledge of their actual family income. Furthermore, measures of distractions in the victim's primary supervisor's life may have not been apparent to the JSO (e.g., whether or not the parent is trying to keep a romantic relationship together or suffers from a drug or alcohol problem). Despite this limitation, 
gathering data from the JSOs perspective provides real insight into how their understanding of how their environment influences their behavior. Finally, this data was collected between 1998 and 2004, over 10 years previous to the current study. Since that time, there may have been certain cohort effects relating to JSOs routine activities or even their use of modus operandi strategies that may have impacted the results of this study. Future studies replicating these results will determine whether these relationships exist within other cohorts of JSOs

This study draws upon a sample of incarcerated JSOs, providing a great deal of insight into a difficult to access population. A limitation inherent in this sample is that the behaviors of incarcerated JSOs may not be generalizable to other JSOs who have never been apprehended for their crime. Future studies investigating the relationship between JSO supervisor status and their use of modus operandi strategies may want to compare incarcerated JSOs to those in outpatient treatment. Outpatient JSOs may differ from incarcerated JSOs in terms of the severity of their crime, their ability to conceal certain pieces of their crimes, or their access to economic resources. Furthermore, this study did not find differences in JSO modus operandi behaviors according the JSO's geographic location (i.e., the state in which they were incarcerated), but future studies should investigate this further, as state law dictates which JSOs get incarcerated. Differences in state law may impact incarcerated JSO's reported use of modus operandi behaviors. It is also important to note that since the sample consisted solely of JSOs, these results are not generalizable to all adolescent babysitters.

Another limitation that is important to consider is the measurement of victim characteristics. JSO-victim relationships were operationalized based on both the age and 
gender of the last victim the JSO offended against. This is the same victim for whom the participant was thinking of, and referring to, while responding to the questionnaires. It is likely however that some of the JSOs who had more than one victim may have abused against victims with different characteristics. It is possible that offenders with multiple victims may have reported differently if they had been asked to report about the full spectrum of their victims. Despite this limitation, participant responses still reveal important details about their relationship with that particular victim.

The measurement of whether or not a JSO counted as a supervisor was assessed using a single questionnaire item. In an attempt to remedy this limitation, two other measurements of supervision were compared to the item. First, there was a box that stated "If YOU were the child's supervisor during any of the times you were abusing him/her, check here and skip to question 4." This was only moderately correlated to our dependent variable $r(333)=.457(p=.00)$, despite being similarly phrased and located on the same page of the questionnaire. The item chosen for the dependent variable instead was written as part of a larger question in which respondents were asked to indicate all people who were responsible for supervising the victim while they were being abused. This may have been more valid than the "check here" box, because it asked respondents to consider the range of the victim's supervision with more specificity. In an attempt to further validate the variable in question, a new variable was created in which responses to two items: "How often were you asked to babysit the child by the child's supervisor," and "how often were you offering to babysit the child," were dummy coded such that respondents were assigned a 1 if they responded affirmatively to either item, and assigned a 0 if they reported never asking, or being asked to supervise. This resulting variable was not highly 
correlated with either the unused supervision variable $r(335)=.322(p=.00)$, or the dependent variable $r(335)=.367(p=.00)$. This is not entirely surprising, because there are situations in which a JSO could be supervising their victim without either asking to supervise or being asked to supervise. Perhaps the JSO assumed the responsibility due to an absence of a parent or adult supervisor. The JSO may have also been asked to supervise the victim by someone other than the victim's primary supervisor. This study makes an important contribution to the child sexual abuse literature through the examination of modus operandi through the lens of JSO supervisor status, however it will be important for future studies to validate this particular measure of supervision (Schwebel \& Kendrick, 2009). This can be through additional studies of JSO modus operandi that include measures of specific types of supervision, ranging from JSOs who only assist with childcare in the presence of the child's parent, to JSOs who are hired as long term babysitters for their victim. Future studies should also investigate whether JSOs self-reports as their victim's supervisor coincide with the report of the victim's parent (Schwebel \& Kendrick, 2009).

Due to the cross-sectional, non-experimental design of the study, causal inferences cannot be formed. As such, the direction of relationships examined in this study cannot be determined. Temporary supervisors or babysitters may develop authority as a result of becoming a supervisor, or they may be chosen for exhibiting that very trait. Furthermore, a third unknown variable may be driving the relationship. Regardless of the direction of the relationship, this study's findings will have implications for prevention if JSO perpetrated CSA, particularly with regard to distinct patterns of grooming that are difficult to detect (Elliot, Browne \& Kilcoyne, 1995; Kaufman, Hayes \& Knox, 2012; 
Kaufman Hilliker \& Daleiden, 1996). For example, parents need to be educated about subtler grooming patterns displayed by JSOs that are more difficult to detect (e.g., gift giving or offering special privileges to a child; Kaufman, Hilliker \& Daleiden, 1996; Wortley \& Smallbone, 2006).

While it can be tempting to view these results as a caution against the use of teenage babysitters at all, that is not the intended recommendation of this study for several reasons. Even though several of the analyses reached statistical significant, their effect sizes were still quite small. As such, statistical significance in this study does not necessarily equate with clinical significance. For example, the finding that JSO supervisors used grooming strategies more frequently than non-supervisors explained only $2 \%$ of the variance. Future research is needed to better understand what makes up the remaining $98 \%$ of variance. Potential factors could include perpetrator-specific factors such as personality traits or socio-economic status, or victim-specific factors such as number of other family members living in the home.

There are also practical reasons why parents should not avoid the use of adolescent babysitters. First, many families have limited resources for childcare and may depend on adolescents for assistance (Leclerc \& Felson, 2014). Second, there are numerous benefits to having teenagers supervise younger children, and in a majority of cases, teenagers can be trusted to appropriately supervise children. Instead, these results should be used to strengthen prevention efforts, such that parents can be made aware of ways to increase the quality and quality of supervision and monitoring provided to their children's babysitters (Leclerc, Benoit, Proulx, Beauregard, 2009; Leclerc, Carpentier, \& Proulx, 2006). Prevention may need to more often incorporate practical and direct 
strategies to ensure children's safety (e.g., more frequent "surprise visits," more active adult supervision or other "guardians" to ensure safety), even in cases where the adolescent in charge is trusted and capable. It is also important that any suggestions or signs of child sexual abuse should be taken seriously by parents and other adult supervisors (Leclerc et al., 2009; Leclerc \& Felson, 2014). Together, the results of this study suggest a variety of interesting implications for future research, prevention, and the effective treatment of JSOs.

\section{Future Directions}

This study's findings reveal a number of important future directions for research in this area. First, a more in-depth examination of babysitters and temporary supervisors as a subtype of JSO offenders is warranted. It is likely that other subgroup differences exist within this group that relate to the use of modus operandi strategies in ways that were not revealed in this study. For example, there may be appreciable differences in the effect of JSO supervisor status when the frequency and duration of supervision is considered, or whether or not the offender lives with their victim is taken into account (Leclerc, Smallbone and Wortley, 2013). There may also be differences between selfappointed supervisors and supervisors as reported by the victim's parent. It is possible that JSOs who act as supervisors on a more frequent or intensive basis may more closely resemble adult offenders, in terms of grooming patterns, as originally hypothesized (Kaufman et al., 1998). Replicating this study with a measure of supervision which focuses more closely on issues described in this study should be considered. For instance, it may be useful to investigate differences in modus operandi between JSOs who are trusted to watch young children without an adult on a regular basis versus occasional 
babysitters and non-babysitters. Using a multi-method assessment approach may also yield significant findings that were not identified in this study. Structured interviews and open ended questions, as well as more focused "pencil-and-paper" measures may provide additional insights in this area of inquiry.

Another important future research direction for this research involves investigating more detailed and varied data regarding routine activities (Cohen \& Felson 1979; Kaufman et al., 2006; Tewksebury, Mustaine \& Stengel, 2008). For example, the number of hours a caregiver works and the number of other children in the household might influence a JSO's modus operandi in ways that are different from the more subjective self-report measurements utilized in this study. In cases in which the JSO and their victim do not share a primary supervisor (e.g., not children of the same parent), it would be useful to measure the routine activities of the JSO's supervisor, as well. It is possible that JSOs engage in different patterns of modus operandi strategies based on the routine activities of multiple adults, or potential guardians, in their own lives (i.e., separate from the routine activities of the victim's supervisor). Routine activities are a central factor in theory-based crime-prevention, including the Situational Prevention Approach to child sexual abuse, and further establishing the routine activities of victims, offenders and supervisors in cases of CSA can have immediate practical implications (Kaufman Hayes \& Knox, 2012; Leclerc, Smallbone and Wortley, 2013).

In conclusion, this study attempted to address gaps in the literature regarding JSOs use of modus operandi strategies. Understanding the routine activities of supervisors and how they contribute to their use of adolescents for their childcare needs has important implications for the development of CSA prevention strategies (Kaufman, 
Hayes \& Knox 2012; Finkelhor \& Baron, 1986; Leclerc, Smallbone and Wortley, 2013). The results from this study not only have important implications for research and practice regarding CSA perpetrated by juveniles, it also expands on child supervision research through the use of a unique and highly contextual measurement of supervision (Saluja et al., 2004; Schwebel \& Kendrick, 2009; Tewksebury, Mustaine \& Stengel, 2008). 
Table 1. Adolescent Modus Operandi Questionnaire Subscale Items* (Internal Consistency)

\begin{tabular}{|c|c|}
\hline PART ONE: Gaining Trust $(.92 \alpha)$ & $\begin{array}{l}\text { PART TWO: Bribes and Enticements for } \\
\text { Gaining Victim Compliance }(.94 \alpha)\end{array}$ \\
\hline $\begin{array}{l}\text { Love and Attention }(\mathbf{9 2} \boldsymbol{\alpha}) \\
\text { Spend a lot of time with them } \\
\text { Give them a lot of attention } \\
\text { Tell them they're special } \\
\text { Take them places } \\
\text { Talk like their age } \\
\text { Trick them into feeling safe with you } \\
\text { Say loving, caring things to them } \\
\text { Touch them non-sexually } \\
\text { Let them decide what you will do together } \\
\text { Protect them from people who might hurt } \\
\text { them } \\
\text { Play with them } \\
\text { Do what they like to do } \\
\text { Giving Gifts (.86 } \alpha) \\
\text { Give them candy or favorite food } \\
\text { Give them toys } \\
\text { Give them privileges or rewards } \\
\text { Give them money }\end{array}$ & $\begin{array}{l}\text { Exposure to Pornography }(\mathbf{8 3} \boldsymbol{\alpha}) \\
\text { Have them watch you do sexual things with other kids } \\
\text { Show them media with naked adults } \\
\text { Show them media with adults doing sexual things together } \\
\text { Show them media with adults doing sexual things with kids } \\
\text { Show them media with naked children } \\
\text { Show them media with kids doing sexual things together } \\
\text { Show them media with animals doing sexual things } \\
\text { Show them media with people doing sexual things with } \\
\text { animals }\end{array}$ \\
\hline 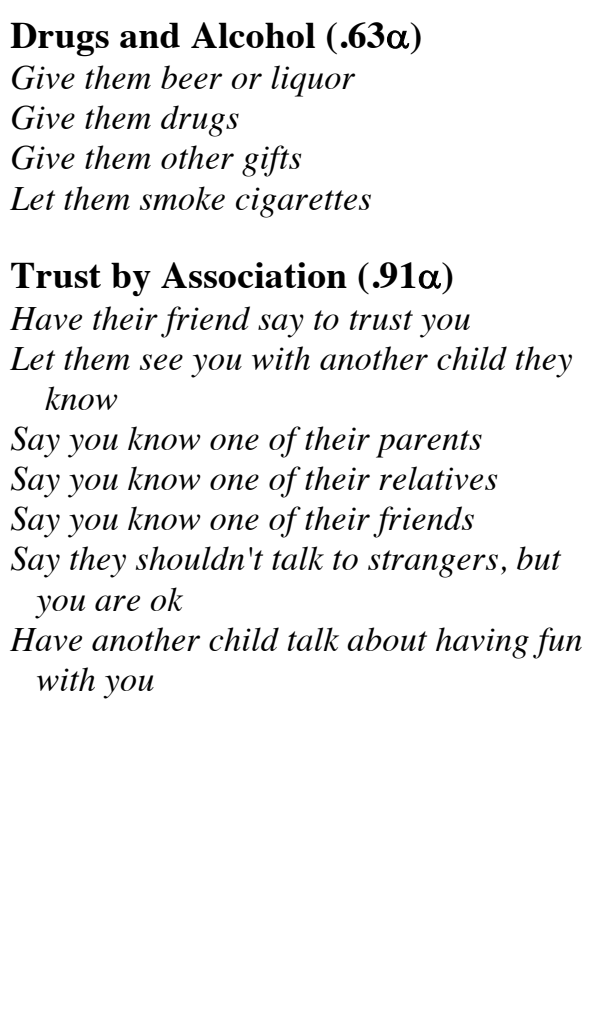 & $\begin{array}{l}\text { Desensitizing the Victim to Sexual Contact (.88 } \mathbf{\alpha}) \\
\text { Talk more and more about sex } \\
\text { Wear less clothes and tell child to wear less } \\
\text { Touch them more and more } \\
\text { Tell them their friends have already had sex } \\
\text { Start sexual abuse like no big thing } \\
\text { Start sexual abuse when they were upset } \\
\text { Get them curious about sex } \\
\text { Get them sexually excited } \\
\text { Say loving things } \\
\text { Touch them non-sexually } \\
\text { Say nice things about them } \\
\text { Say you will 'teach' them something } \\
\text { Say you will love them more if they do this with you } \\
\text { Say you will take them places } \\
\text { Say you will spend more time with them } \\
\text { Save their friend, who you've been sexual involved } \\
\quad \text { with say it's ok } \\
\text { Giving Gifts and Privileges (.88 } \mathbf{\alpha}) \\
\text { Give them gifts sometimes } \\
\text { Give them candy just after sexual abuse } \\
\text { Give them money just after sexual abuse } \\
\text { Give them toys just after sexual abuse } \\
\text { Give them privileges or rewards just after sexual abuse }\end{array}$ \\
\hline
\end{tabular}

*Participant reported how often then used this strategy for the purpose of engaging in child sexual abuse $(0=$ never, $3=$ almost always $)$ 
Table 1. Adolescent Modus Operandi Questionnaire Subscale Items* (Internal Consistency)

\begin{tabular}{ll}
\hline PART THREE: Threats to Gain Victim & PART FOUR: Keeping the Victim Quiet \\
Compliance $(.92 \alpha)$ & about the Sexual Contact $(.92 \alpha)$
\end{tabular}

Making the Victim Feel Helpless $(.87 \alpha)$

Say you will tell on them about having sex with you

Say you will make up things to tell on them

Make them feel like there is nothing to do to stop it

Say you will hit them if they don't do it

Say they don't love you if they don't do sexual things

Use force to make them do sexual things

Hope they thought you would hurt them

Hope they thought you would hurt a family member

Hope they thought you would get them in trouble

\section{Threatening to Harm Others (.93 $\alpha)$}

Say you will hurt their siblings

Say you will hurt their mother

Say you will hurt their father

Say you will hurt their friends or relatives

Say you will kill their sibling

Say you will kill their mother

Say you will kill their father

Say you will their friends or relatives

\section{Psychopathy $(.85 \alpha)$}

Say you will hurt their pet

Say you will kill their pet

Get them drunk

Get them high with drugs

Get them high with prescription drugs

Hurt a pet in front of them

\section{Use of a Weapon $(.81 \alpha)$}

Put a weapon where they could see

Say you will hurt them with a gun

Say you will hurt them with a knife

Say you will hurt them with another object

Say you will kill them
Benefits and Consequences for the Victim or the Offender $(.89 \alpha)$

Say you will give privileges of if they don't tell

Say you will take them places if they don't tell

Say you will spend more time together if they don't tell

Say you will love them more if they don't tell

Say you cannot spend time together if anyone knew

Say you cannot go places together if anyone knew

Say you cannot buy but them things if anyone knew

Say their parents would not love them anymore

Say that you would not love them anymore

Say you would tell on them about their sexual activity

Say you would tell on them about bad behaviors

Take away love or affection as warning

Hope they wouldn't want to lose you

Threatening to Harm the Victim $(.79 \alpha)$

Say they would get in trouble if they told

Say you would hurt them with a gun

Say you would hurt them with a knife

Say you would hurt them with another object

Hurt them as warning

Hope they thought it was their fault

Hope they thought you would hurt them

Hope they thought you would get them in trouble

\section{Threatening to Harm Others (.94 $\alpha$ )}

Say you would hurt their siblings

Say you would hurt their mother

Say you would hurt their father

Say you would hurt their friends or relatives

Say you would kill their siblings

Say you would kill their mother

Say you would kill their father

Say you would kill their friends or relatives

Say you would kill their pet

*Participant reported how often then used this strategy for the purpose of engaging in child sexual abuse $(0=$ never, $3=$ almost always $)$ 
Table 2. Supervision Questionnaire Subscale Items* (Internal Consistency)

\section{JSO Efforts to Get the Child Alone (.85 $\alpha)$}

During the times when the abuse occurred, how often did you: *

Offer to babysit

Attempt to get the child alone

Volunteer to help child get dressed or undressed

Volunteer to help child take a bath

Volunteer to help child get ready for bed

Volunteer to help child eat or take care of him/herself

Volunteer to help play games with the child

Volunteer to help check on child during the night

\section{Parents Need for Childcare Assistance (.91 $\alpha$ )}

During the times when the abuse occurred, how often did the parent: *

Ask you to babysit

Ask you to watch the child while they are elsewhere in their house

Ask you to watch the child while they run errands

Leave the child alone

Leave the child in your care

\section{Factors that Interfere with Parent's Ability to Adequately Care for their Child}

\section{(i.e., Disruptions to Supervision; $.99 \alpha)$}

How often did the following things get in the way of the supervisor's ability to monitor the child? *

The parent was working too many hours

The parent had too many other family members to care for

The parent was trying to keep a marital or dating relationship

The child was visiting with his or her other parent

The parent was suffering from emotional problems

The parent was suffering from physical/health problems

The parent was suffering from domestic violence

The parent was using drugs and/or alcohol

$*(0=$ never, $4=$ always $)$ 
Table 3. Modus Operandi Group Mean Scores

\begin{tabular}{|c|c|c|}
\hline & \multicolumn{2}{|c|}{ Mean Scores (Standard Deviation)* } \\
\hline & JSO Supervisors & $\begin{array}{l}\text { JSO Non- } \\
\text { Supervisors }\end{array}$ \\
\hline $\begin{array}{l}\text { Bribes and enticements to gain victim } \\
\text { compliance }\end{array}$ & $.46(.33)$ & $.34(.43)$ \\
\hline Buying the victim clothing & $.12(.40)$ & $.14(.45)$ \\
\hline Drugs and alcohol & $.20(.59)$ & $.12(.48)$ \\
\hline Exposure to pornography & $.23(.30)$ & $.21(.47)$ \\
\hline Engagement in Pornography & $.10(.24)$ & $.13(.43)$ \\
\hline Desensitization to sexual contact & $.99(.70)$ & $.75(.75)$ \\
\hline Giving gifts and privileges & $1.11(.99)$ & $.67(.86)$ \\
\hline $\begin{array}{l}\text { Threats and coercion to gain victim } \\
\text { compliance }\end{array}$ & $.18(.23)$ & $.19(.37)$ \\
\hline Threatening to harm others & $.06(.23)$ & $.10(.38)$ \\
\hline Making the victim feel helpless & $.54(.61)$ & $.40(.62)$ \\
\hline Use of a weapon & $.07(.28)$ & $.14(.41)$ \\
\hline Psychopathy & $.06(.22)$ & $.10(.34)$ \\
\hline $\begin{array}{l}\text { Strategic Grooming (i.e., overall score } \\
\text { across the } 4 \text { modus operandi categories) }\end{array}$ & $.48(.33)$ & $.36(.41)$ \\
\hline
\end{tabular}

$* 0=$ never used this strategy, $3=$ almost always used this strategy 


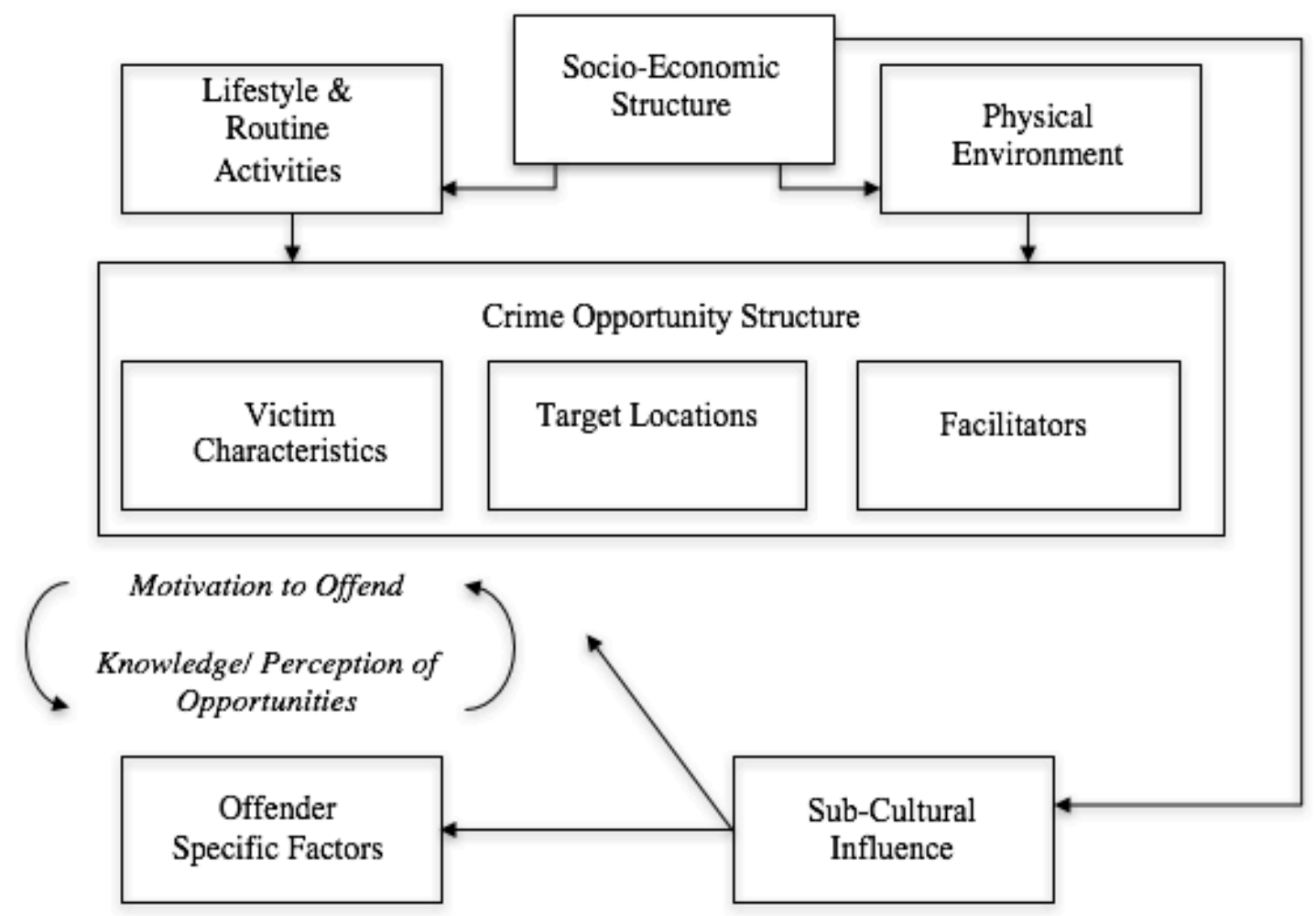

Figure 1.

The Situational Prevention Model for Child and Adolescent Sexual Abuse 


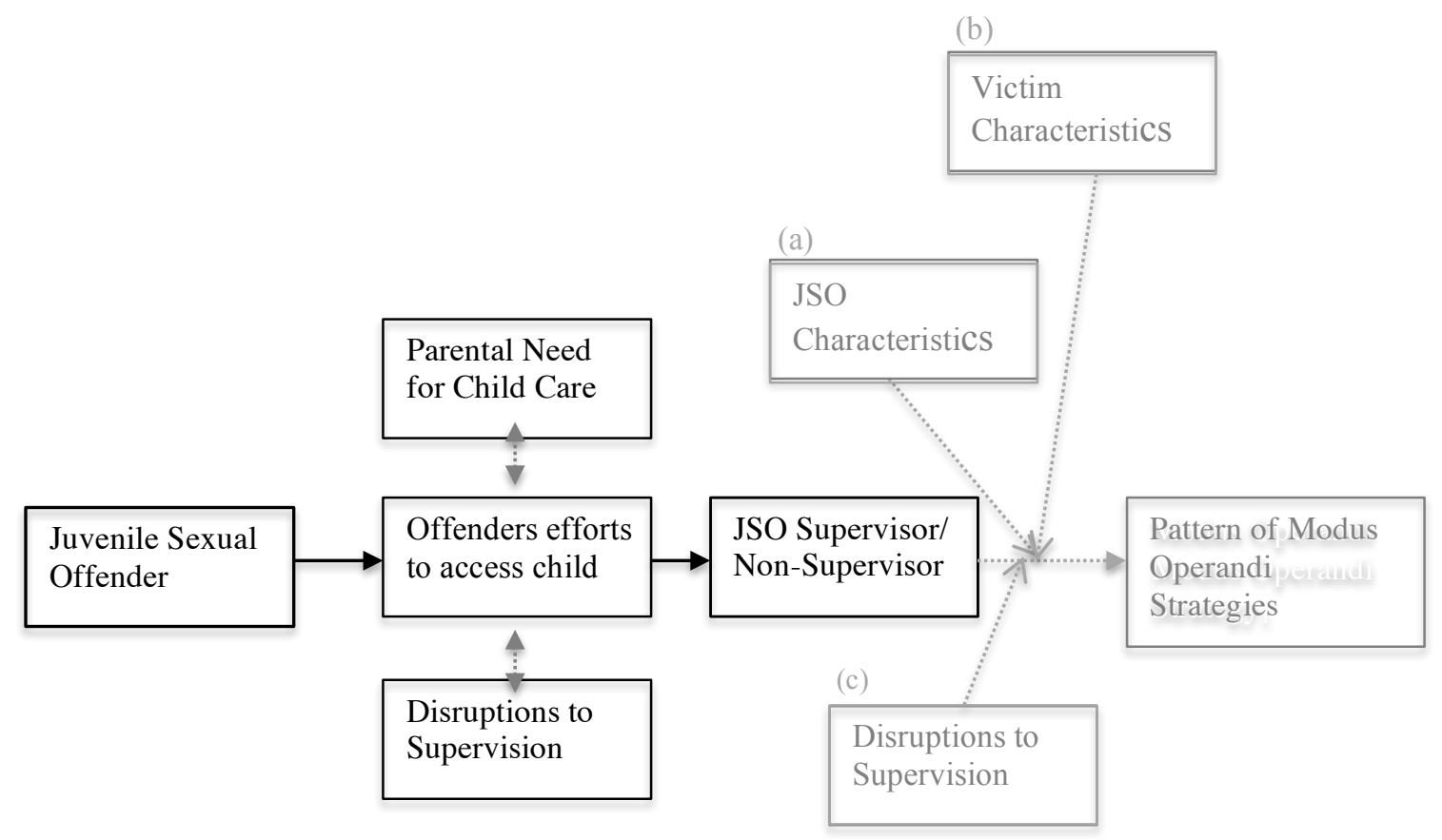

Figure 2.

Research Question 1: Becoming a Supervisor

(a) Hypothesis 1a (H1a)

(b) Hypothesis $1 \mathrm{~b}(\mathrm{H} 1 \mathrm{~b})$

(c) Hypothesis 1c (H1c) 


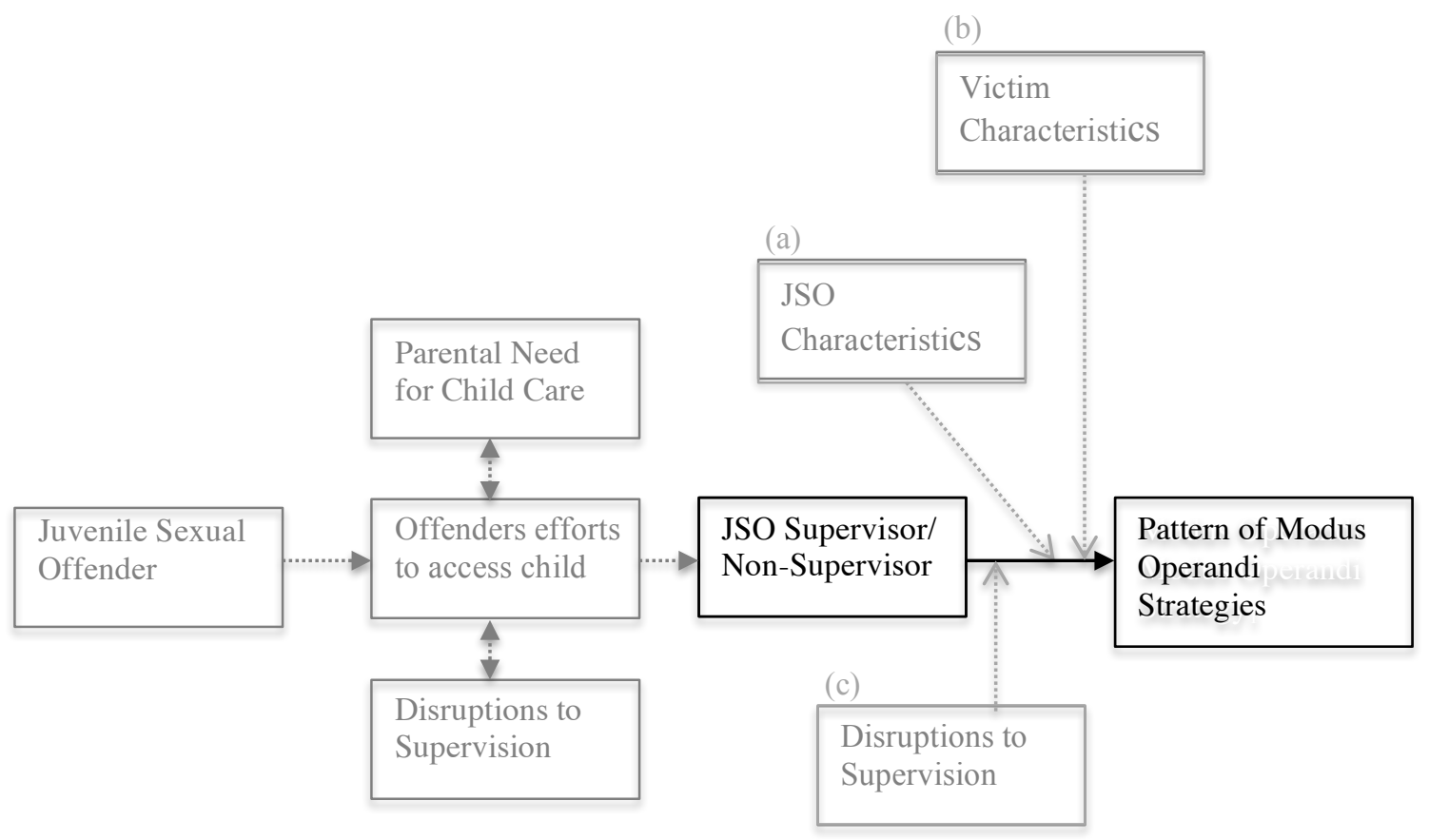

Figure 3.

Research Question 2: Strategic Grooming

(a) Hypothesis 2a (H2a)

(b) Hypothesis $2 \mathrm{~b}(\mathrm{H} 2 \mathrm{~b})$

(c) Hypothesis 2c $(\mathrm{H} 2 \mathrm{c})$ 
(b)

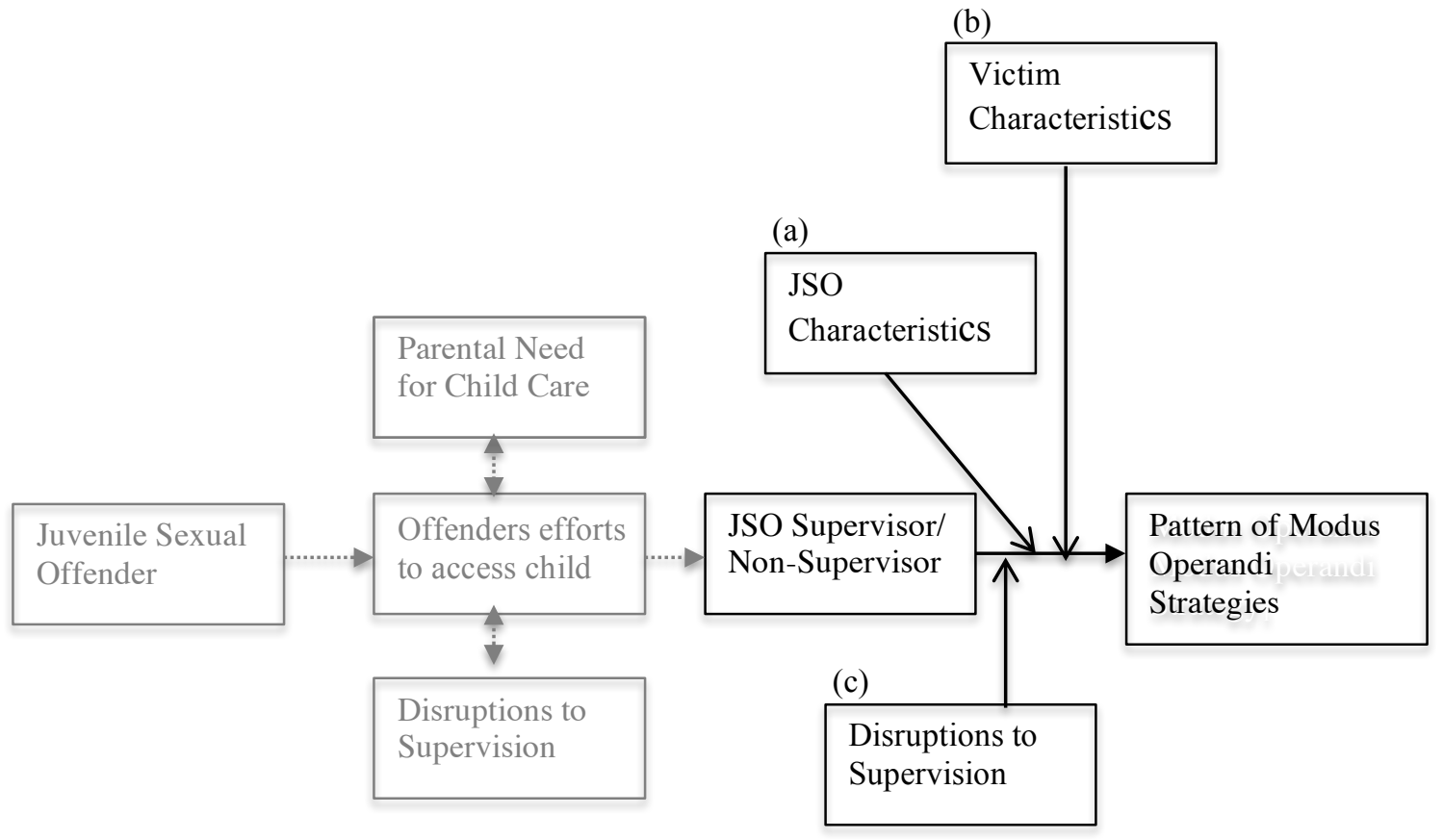

Figure 4.

Research Question 3: Factors that Moderate Strategic Grooming

(a) Hypothesis 3a (H3a)

(b) Hypothesis $3 \mathrm{~b}(\mathrm{H} 3 \mathrm{~b})$

(c) Hypothesis $3 \mathrm{c}(\mathrm{H} 3 \mathrm{c})$ 


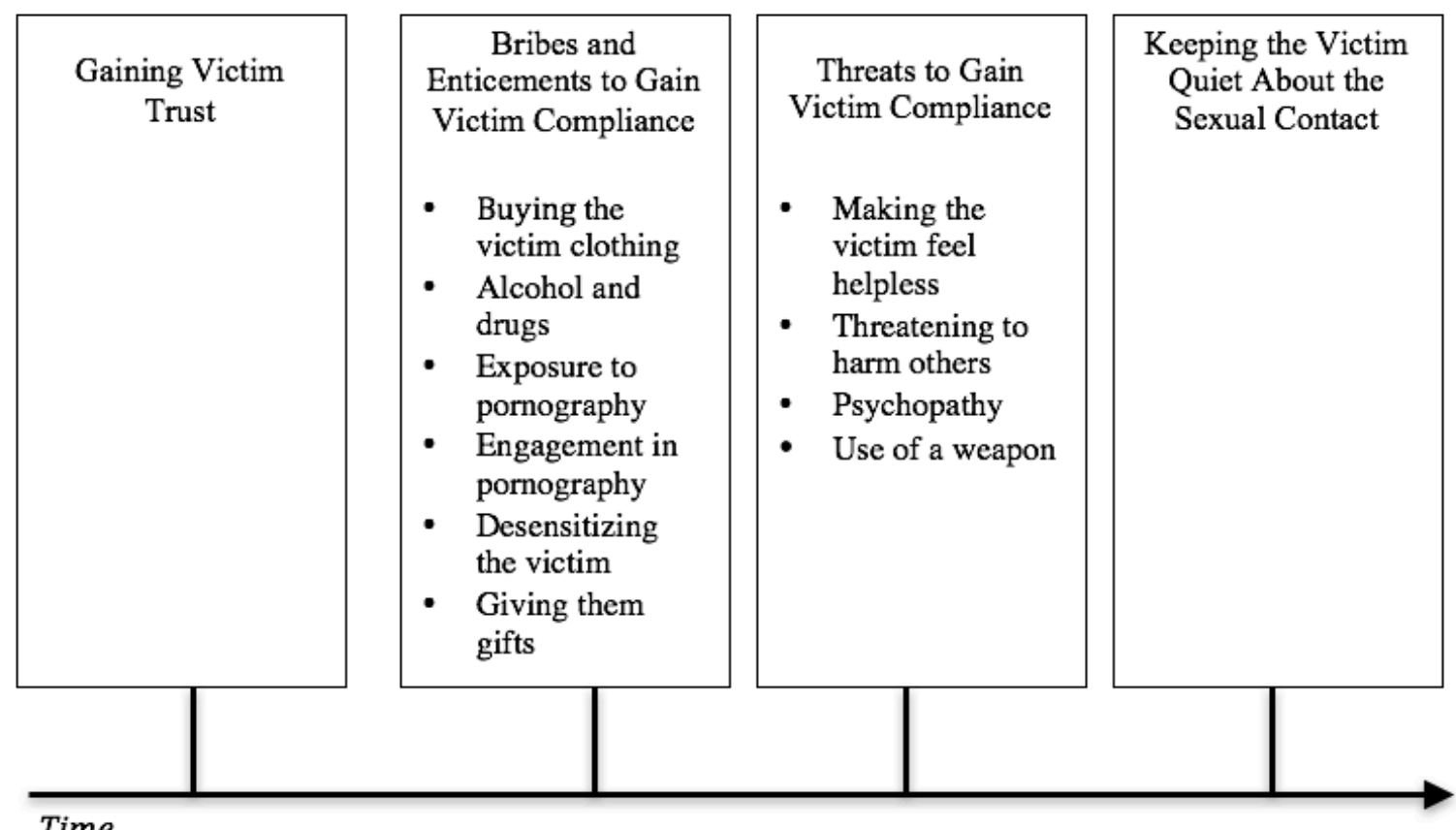

Time

Figure 5.

Adolescent Modus Operandi Questionnaire Continuum of Abuse 


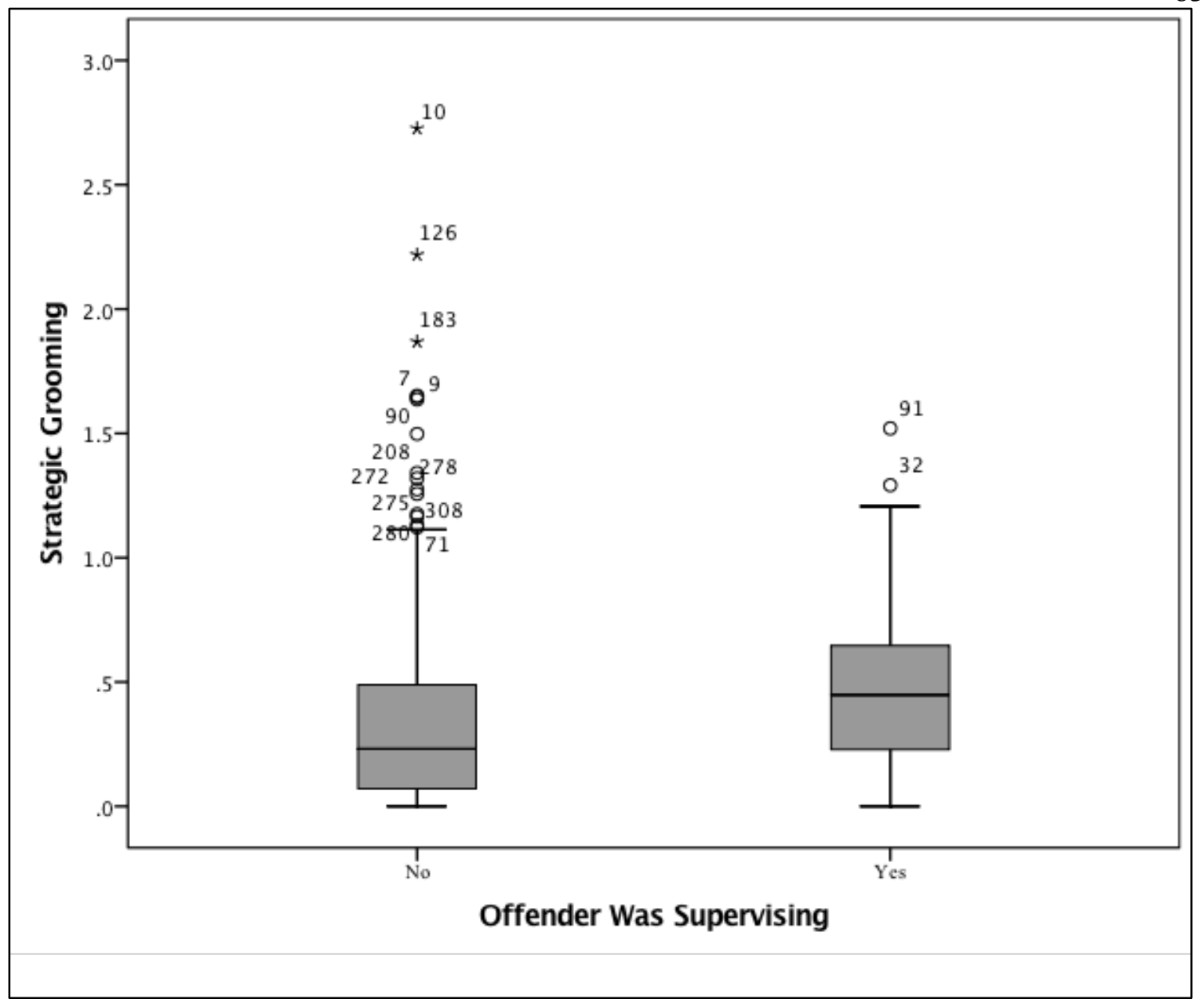

Figure 6.

Group Distribution of Strategic Grooming Scores 


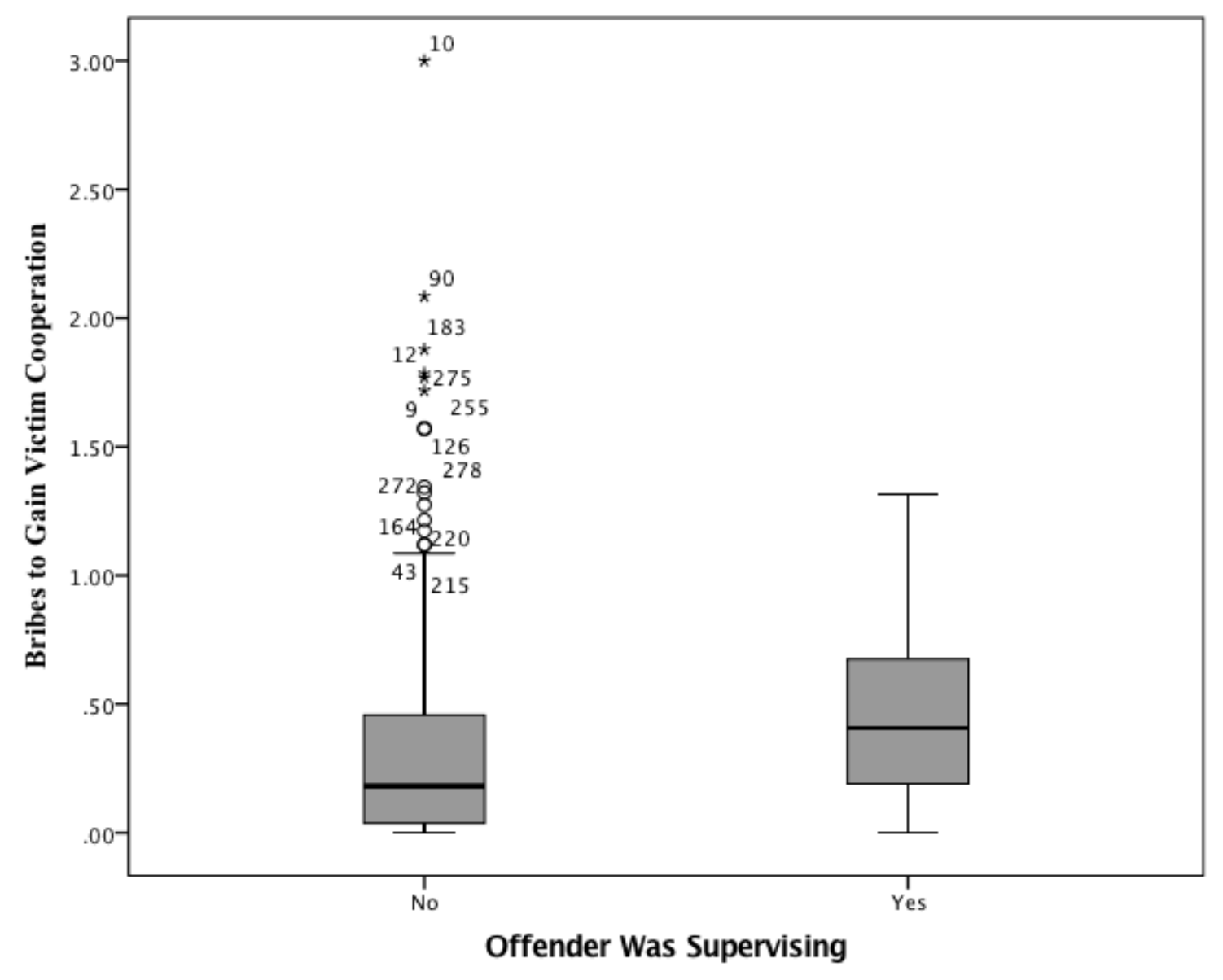

Figure 7.

Group Distribution of Bribes to Gain Victim Compliance Scores 


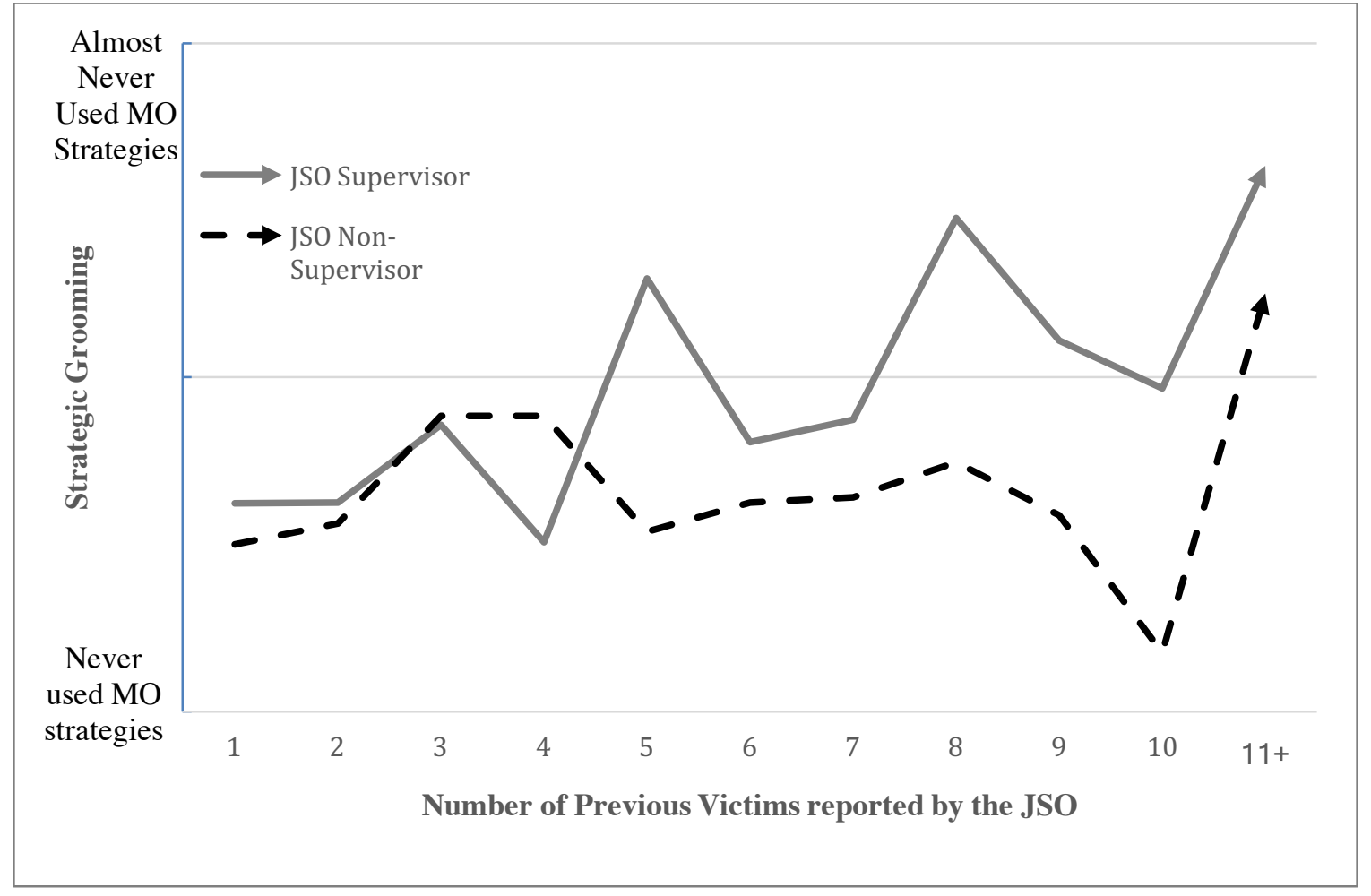

Figure 8.

Average Frequency of Modus Operandi Strategies Used According to JSO Supervisor Status and Number of Previous Victims 


\section{References}

Abel, G.G., Osborne, C.A, and Twigg (1993) 'Sexual Assault Throughout the Lifespan: Adult offenders with juvenile histories'. In W. L. Marshall, H.E. Barbaree and S.M. Hudson (Eds.) The Juvenile Sex Offender. New York: Guilford Press, pp. 104-117.

Aebi, M., Vogt, G., Plattner, B., Steinhausen, H. C., \& Bessler, C. (2012). Offender types and criminality dimensions in male juveniles convicted of sexual offenses. Sexual Abuse: a Journal of Research and Treatment, 24(3), 265-288.

American Academy of Pediatrics (1999). Guidelines for the evaluation of sexual abuse of children: Subject review. Pediatrics, 103(1), 186-91.

Bagley, C., Thurston, W.E. and Tutty, L.M. (1996) Understanding and Preventing Child Sexual Abuse, Vol. 1: Children: Assessment, Social Work and Clinical Issues. Aldershot: Ashgate Publishing.

Baker, A. W., \& Duncan, S. P. (1985). Child sexual abuse: a study of prevalence in Great Britain. Child Abuse \& Neglect, 9(4), 457-467.

Baker, T.A., Connaughton, D.P., \& Zhang, J.J. (2010). An examination of immunity statutes regarding the liability of recreational youth sport organizations for the pedophilic actions of coaches, administrators, and officials. Journal of Research in Health, Physical Education, Recreation, Sport \& Dance, 5(1), 54-59.

Beauregard, E., Rossmo, D. K., \& Proulx, J. (2007). A Descriptive model of the hunting process of serial sex offenders: A rational choice perspective. Journal of Family Violence, 22(6), 449-463. doi:10.1007/s10896-007-9101-3. 
Beauregard, E., Proulx, J., Rossmo, K., Leclerc, B., \& Allaire, J. F. (2007). Script analysis of the hunting process of serial sex offenders. Criminal Justice and Behavior, 34(8), 1069-1084.

Beitchman, J. H., Zucker, K. J., Hood, J. E., \& Akman, D. (1991). A review of the short term effects of child sexual abuse. Child Abuse \& Neglect, 15(4), 537-556.

Boyle, P. (2014). How youth-serving organizations enable acquaintance molesters. Journal Interpersonal Violence, 1-10.

Brown, J., Cohen, P., Johnson, J. G., \& Salzinger, S. (1998). A longitudinal analysis of risk factors for child maltreatment: Findings of a 17-year prospective study of officially recorded and self-reported child abuse and neglect. Child Abuse \& Neglect, 22(11), 1065-1078.

Browne, A., \& Finkelhor, D. (1986). Impact of child sexual abuse: A review of the research. Psychological Bulletin, 99(1), 66.

Butchart, A., Harvey, A. P., Mian, M., \& Furniss, T. (2006). Preventing child maltreatment: a guide to taking action and generating evidence.

Centers for Disease Control and Prevention. (2004). Sexual violence prevention: Beginning the dialogue. Atlanta, GA: Centers for Disease Control and Prevention.

Centers for Disease Control and Prevention, National Center for Injury Prevention and Control (2007). Preventing Child Sexual Abuse Within Youth-serving Organizations: Getting Started on Policies and Procedures. Retrieved December 21,2014 from http://www.cdc.gov/violenceprevention/pdf/PreventingChildSexualAbusea.pdf\#page $=14$ 
Clarke, R. V. (1995). Situational crime prevention. In M. Tonry \& D. Farrington (Eds.), Building a safer society: Strategic approaches to crime prevention. Crime and Justice: An Annual Review of Research, Vol. 19. (pp. 91-150). Chicago: University of Chicago Press.

Clarke, R. \& Homel, R. (1997). A revised classification of situational crime prevention Techniques. In S.P. Lab (Ed.), Crime Prevention at a Crossroads (pp. 17-30). Cincinnati: Anderson Publishing Co. and Academy of Criminal Justice Sciences.

Cohen, L. E., \& Felson, M. (1979). Social change and crime rate trends: A routine activity approach. American Sociological Review, 588-608.

Colton, M., Roberts, S., \& Vanstone, M. (2010). Sexual abuse by men who work with children. Journal of Child Sexual Abuse, 19, 345-364.

Cornish, D., \& Clarke, R. (1986). Situational prevention, displacement of crime and rational choice theory. Situational Crime Prevention: From Theory into Practice, London: HMSO, 1-16.

Cornish, D. B., \& Clarke, R. V. (2002). Analyzing organized crimes. In A. R. Piquero \& S. G. Tibbetts (Eds.), Rational Choice and Criminal Behaviour: Recent Research and Future Challenges (pp. 41-63). New York: Routledge.

Cortoni, F. and Hansen, R.K. (2005) A Review of the Recidivism Rates of Adult Female Sexual Offenders, Research Report No. R-169. Ottawa, ON; Correctional Service of Canada.

Crosson-Tower, C. (2005). Extrafamilial sexual abuse, misuse, and exploitation. In Understanding Child Abuse and Neglect. Retrieved from http://www.pearsonhighered.com/samplechapter/020540183X.pdf 
Demo, David H. (1992). Parent-child relations: Assessing recent changes. Journal of Marriage and Family, 54, 104-117.

De Souza, E., \& Miller, J. (2012). Homicide in the Brazilian Favela: Does opportunity make the killer? British Journal of Criminology, 52(4), 786-807. doi:10.1093/bjc/azs011

Dishion, T. J., \& McMahon, R. J. (1998). Parental monitoring and the prevention of child and adolescent problem behavior: A conceptual and empirical formulation. Clinical Child and Family Psychology Review, 1, 61-75.

Efta-Breitbach, J., \& Freeman, K. A. (2004). Treatment of juveniles who sexually offend: An overview. Journal of Child Sexual Abuse, 13(3-4), 125-138.

Elliot, M., Browne, K. and Kilcoyne, J (1995). Child sexual abuse prevention: What offenders tell us, Child Abuse and Neglect, 19(5): 579-594.

Esbensen, F. A., Huizinga, D., \& Menard, S. (1999). Family context and criminal victimization in adolescence. Youth \& Society, 31(2), 168-198.

Fanniff, A. M., \& Kolko, D. J. (2012). Victim age-based subtypes of juveniles adjudicated for sexual offenses: comparisons across domains in an outpatient sample. Sexual Abuse: A Journal of Research and Treatment, 24(3), 224-64. doi: $10.1177 / 1079063211416516$

Felson, M. (1995). Those who discourage crime. In J. E. Eck \& D. Weisburd (Eds.), Crime pre- vention studies: Vol. 4. Crime and place (pp. 53-66.). Monsey, NY: Criminal Justice Press.

Finkelhor, D., \& Asdigian, N. L. (1996). Risk factors for youth victimization: Beyond a lifestyles/routine activities theory approach. Violence and Victims,11(1), 3-19. 
Finkelhor, D., \& Baron, L. (1986). Risk factors for child sexual abuse. Journal of Interpersonal Violence, 1(1), 43-71. doi:10.1177/088626086001001004

Finkelhor, D., Ormrod, R., \& Chaffin, M. (2009). Juveniles who commit sex offenses against minors. US Department of Justice, Office of Justice Programs, Office of Juvenile Justice and Delinquency Prevention.

Fischer, D. G., \& McDonald, W. L. (1998). Characteristics of intrafamilial and extrafamilial child sexual abuse. Child Abuse \& Neglect, 22(9), 915-929.

Galesic, M., \& Bosnjak, M. (2009). Effects of questionnaire length on participation and indicators of response quality in a web survey. Public Opinion Quarterly, 73(2), 349-360.

Gallagher, B. (1999). The abuse of children in public care. Child Abuse Review, 8, 357 365.

Groff, E. R. (2007). Simulation for theory testing and experimentation: An example using routine activity theory and street robbery. Journal of Quantitative Criminology, 23(2), 75-103. doi:10.1007/s10940-006-9021-z

Guerette, R. T., \& Bowers, K. J. (2009). Assessing the extent of crime displacement and diffusion of benefits: a review of situational crime prevention evaluations*. Criminology, 47(4), 1331-1368.

Henggeler, S. W., Letourneau, E. J., Chapman, J. E., Borduin, C. M., Schewe, P. A., \& McCart, M. R. (2009). Mediators of change for multisystemic therapy with juvenile sexual offenders. Journal of Consulting and Clinical Psychology, 77(3), 451.

Kaufman, K.L. (1994). Adolescent Modus Operandi Questionnaire. Revised Version. 
Columbus, Ohio: Author. (Children's Hospital).

Kaufman, K. L., Hilliker, D. R., \& Daleiden, E. L. (1996). Subgroup differences in the modus operandi of adolescent sexual offenders. Child Maltreatment, 1(1), 17-24.

Kaufman, K. L., Holmberg, J. K., Orts, K. A., McCrady, F. E., Rotzien, A. L., Daleiden, E. L., \& Hilliker, D. R. (1998). Factors influencing sexual offenders' modus operandi: An examination of victim-offender relatedness and age. Child Maltreatment, 3(4), 349-361.

Kaufman, K., Hayes, A., \& Knox, L. A. (2010). The Situational Prevention Model: Creating safer environments for children and adolescents.

Kaufman, K., Mosher, H., Carter, M., \& Estes, L. (2006). An empirically based situational prevention model for child sexual abuse. In R.K. Wortley \& S. W. Smallbone (Eds.) Situational Prevention of Child Sexual Abuse, Crime Prevention Studies, Vol. 19.(pp. 101-144). Monsey, NY: Criminal Justice Press.

Kendall-Tackett, K. A., \& Simon, A. F. (1992). A comparison of the abuse experiences of male and female adults molested as children. Journal of Family Violence, 7(1), $57-62$.

Ketring, S. A., \& Feinauer, L. L. (1999). Perpetrator-victim relationship: Long-term effects of sexual abuse for men and women. American Journal of Family Therapy, 27(2), 109-120.

Lanning, K.V. \& Dietz, P. (2014). Acquaintance molestation and youth-serving organizations. Journal of Interpersonal Violence, 1-24.

Leclerc, B., Carpentier, J., \& Proulx, J. (2006). Strategies adopted by sexual offenders to 
involve children in sexual activity. In R. Wortley \& S. Smallbone (Eds.), Situational prevention of child sexual abuse. Crime Prevention Studies, Vol. 19. (pp. 251-270). Monsey, N.Y.: Criminal Justice Press.

Leclerc, B., Proulx, J., \& Beauregard, E. (2009). Examining the modus operandi of sexual offenders against children and its practical implications. Aggression and Violent Behavior, 14(1), 5-12.

Leclerc, B., Proulx, J., \& McKibben, A. (2005). Modus operandi of sexual offenders working or doing voluntary work with children and adolescents. Journal of Sexual Aggression, 11(2), 187-195.

Leclerc, B., Smallbone, S., \& Wortley, R. (2013). Prevention nearby: The influence of the presence of a potential guardian on the severity of child sexual abuse. Sexual Abuse: A Journal of Research and Treatment, 1079063213504594.

Leclerc, B., \& Felson, M. (2014). Routine Activities Preceding Adolescent Sexual Abuse of Younger Children. Sexual Abuse: A Journal of Research and Treatment. doi:10.1177/1079063214544331

Mannon, J. M. (1997). Domestic and intimate violence: An application of routine activities theory. Aggression and Violent Behavior, 2(1), 9-24.

Parent, S. \& Bannon, J. (2012). Sexual abuse in sport: What about boys? Children and Youth Services Review, 34, 354-359.

Pereda, N., Guilera, G., Forns, M., \& Gómez-Benito, J. (2009). The prevalence of child sexual abuse in community and student samples: A meta-analysis. Clinical Psychology Review, 29(4), 328-338.

Pérez-Fuentes, G., Olfson, M., Villegas, L., Morcillo, C., Wang, S., \& Blanco, C. (2013). 
Prevalence and correlates of child sexual abuse: a national study. Comprehensive Psychiatry, 54(1), 16-27.

Proulx, J., Ouimet, M., \& Lachaine, N. (1995). Criminologie de l'acte pédophilie [Criminology in action and pedophilia]. Revue Internationale de Criminologie et de Police Technique, 48, 294-310.

Putnam, F. W. (2003). Ten-year research update review: Child sexual abuse. Journal of the American Academy of Child \& Adolescent Psychiatry, 42(3), 269-278.

Racz, S. J., \& McMahon, R. J. (2011). The relationship between parental knowledge and monitoring and child and adolescent conduct problems: a 10-year update. Clinical Child and Family Psychology Review, 14(4), 377-98. doi:10.1007/s10567-0110099-y

Renk, K., Liljequist, L., Steinberg, A., Bosco, G., \& Phares, V (2002). Prevention of child sexual abuse: Are we doing enough? Trauma, Violence and Abuse, 3(1), 6884.

Reynald, D. M., \& Elffers, H. (2009). The future of Newman's defensible space theory: Linking defensible space and the routine activities of place. European Journal of Criminology, 6(1), 25-46. doi:10.1177/1477370808098103

Saluja, G., Brenner, R., Morrongiello, B., Haynie., D., Rivera, M., \& Cheng, T. (2004). The role of supervision in child injury risk: Definition conceptual and measurement issues. Injury Control and Safety Promotion, 11(1), 17-22. Retrieved from http://www.tandfonline.com/doi/abs/10.1076/icsp.11.1.17.26310 
Schreck, C. J., \& Fisher, B. S. (2004). Specifying the influence of family and peers on violent victimization: extending routine activities and lifestyles theories. Journal of Interpersonal Violence, 19(9), 1021-41. doi:10.1177/0886260504268002

Smallbone, S., Marshall, W. L., \& Wortley, R. (2013). Preventing child sexual abuse: Evidence, Policy and Practice. Willan.

Smallbone, S.W., and Wortley, R.K. (2004) 'Onset, persistence and versatility of offending among adult males convicted of sexual offences against children', Sexual Abuse, A Journal of Research and Treatment, 164(4): 285-298.

Sullivan, J., \& Beech, A. (2002). Professional perpetrators: Sex offenders who use their employment to target and sexually abuse the children with whom they work. Child Abuse Review, 11(3), 153-167.

Sullivan, J., \& Beech, A. (2004). A comparative study of demographic data relating to intra-and extra-familial child sexual abusers and professional perpetrators. Journal of Sexual Aggression, 10(1), 39-50. doi:10.1080/13552600410001667788

Sullivan, J., Beech, A. R., Craig, L. A., \& Gannon, T. A. (2011). Comparing intra familial and extra-familial child sexual abusers with professionals who have sexually abused children with whom they work. International Journal of Offender Therapy and Comparative Criminology, 55(1), 56-74. doi:10.1177/0306624X09359194

Schwebel, D. C., \& Kendrick, D. (2009). Caregiver supervision and injury risk for young children: time to re-examine the issue. Injury Prevention, 15(4), 217-219.

Schwebel, D. C., Roth, D. L., Elliott, M. N., Windle, M., Grunbaum, J. A., Low, B., Schuster, M. A. (2011). The association of activity level, parent mental distress, and 
parental involvement and monitoring with unintentional injury risk in fifth graders. Accident; Analysis and Prevention, 43(3), 848-52. doi:10.1016/j.aap.2010.11.004

Seto, M. C., \& Lalumiere, M. L. (2010). What is so special about male adolescent sexual offending? A review and test of explanations through meta-analysis. Psychological Bulletin, 136(4), 526.

Smallbone, S. \& Wortley, R. (2000). Child sexual abuse in Queensland: Offender characteristics \& modus operandi, Queensland: Queensland Crime Commission and the Criminology Research Council. Snyder,

Stattin, H., \& Kerr, M. (2000). Parental monitoring: A reinterpretation. Child Development, 71(4), 1072-1085. Retrieved from http://onlinelibrary.wiley.com/doi/10.1111/1467-8624.00210/abstract

Stoltenborgh, M., van Ijzendoorn, M. H., Euser, E. M., \& Bakermans-Kranenburg, M. J. (2011). A global perspective on child sexual abuse: meta-analysis of prevalence around the world. Child Maltreatment, 16(2), 79-101. http://doi.org/10.1177/1077559511403920

Tan, L., \& Grace, R. C. (2008). Social desirability and sexual offenders a review. Sexual Abuse: A Journal of Research and Treatment, 20(1), 61-87.

Terry, K. J. (2008). Stained Glass the Nature and Scope of Child Sexual Abuse in the $\backslash$ Catholic Church. Criminal Justice and Behavior, 35(5), 549-569.

Terry, K. J., Smith, M. L., Schuth, O. S. F., Kelly, C. J. R., \& Vollman, C. B. (2011). The causes and context of sexual abuse of minors by Catholic priests in the United States, 1950-2010. In United States Conference of Catholic Bishops, Washington. 
Tewksbury, R., \& Mustaine, E. (2003). College students' lifestyles and self-protective behaviors: Further consideration of the guardianship concept in routine activities theory. Criminal Justice and Behavior, 30, 302-327.

Tewksbury, R., Mustaine, E. E., \& Stengel, K. M. (2008). Examining Rates of Sexual Offenses from a Routine Activities Perspective. Victims \& Offenders, 3(1), 75-85. doi:10.1080/15564880701752306

Trocmé, N., \& Schumaker, K. (1999). Reported child sexual abuse in Canadian schools and recreational facilities: Implications for developing effective prevention strategies. Children and Youth Services Review, 21(8), 621-642.

Tseloni, A., Wittebrood, K., Farrell, G., \& Pease, K. (2004). Burglary victimization in England and Wales, the United States and the Netherlands. The British Journal of Criminology, 44(1), 66-91.

Tremblay, C., Hébert, M., \& Piché, C. (1999). Coping strategies and social support as mediators of consequences in child sexual abuse victims. Child Abuse \& Neglect, 23(9), 929-945.

Turner, H. A., Finkelhor, D., \& Ormrod, R. (2007). Family structure variations in patterns and predictors of child victimization. American Journal of Orthopsychiatry, 77(2), 282.

Van Wijk, A., Van Horn, J., Bullens, R., Bijleveld, C., \& Doreleijers, T. (2005). Juvenile Sex offenders: A group on its own? International Journal of Offender Therapy and Comparative Criminology, 49(1), 25-36.

Walsh, C., MacMillan, H. L., \& Jamieson, E. (2003). The relationship between parental 
substance abuse and child maltreatment: findings from the Ontario Health Supplement. Child Abuse \& Neglect, 27(12), 1409-1425.

doi:10.1016/j.chiabu.2003.07.002

Well, L. E., \& Rankin, J. H. (1988). Direct parental controls and delinquency. Criminology, 26, 263-285.

Wortley, R. (2001). “A Classification of Techniques for Controlling Situational Precipitators of Crime.” Security Journal 14:63-82.

Wortley, R. (2010). Critiques of situational crime prevention. In Encyclopedia of Victimology and Crime Prevention. (pp. 884-887). Thousand Oaks, CA: Sage Publications, Inc.

Wortley, R. \& Smallbone, S. (2006). Applying situational principles to sexual offenses against children. In R.Wortley \& S. Smallbone (Eds.) Situational prevention of child sexual abuse. Monsey, NY: Criminal Justice Press.

Yar, M. (2005). The novelty of 'cybercrime' an assessment in light of routine activity Theory. European Journal of Criminology, 2(4), 407-427. 